\title{
Viscosity and Strength Properties of Cemented Tailings Backfill with Fly Ash and Its Strength Predicted
}

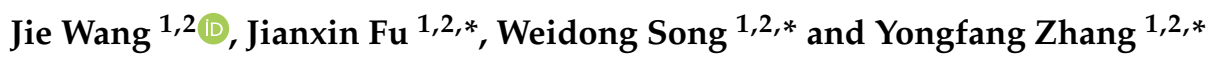 \\ 1 School of Civil and Resources Engineering, University of Science and Technology Beijing, \\ Beijing 100083, China; B20170036@xs.ustb.edu.cn \\ 2 State Key Laboratory of High-Efficient Mining and Safety of Metal Mines of Ministry of Education, \\ University of Science and Technology Beijing, Beijing 100083, China \\ * Correspondence: fjx@ustb.edu.cn (J.F.); songwd@ustb.edu.cn (W.S.); b1903098@ustb.edu.cn (Y.Z.)
}

check for updates

Citation: Wang, J.; Fu, J.; Song, W.; Zhang, Y. Viscosity and Strength Properties of Cemented Tailings Backfill with Fly Ash and Its Strength Predicted. Minerals 2021, 11, 78 . https://doi.org/10.3390/min11010078

Received: 19 November 2020 Accepted: 20 December 2020 Published: 15 January 2021

Publisher's Note: MDPI stays neutral with regard to jurisdictional clai$\mathrm{ms}$ in published maps and institutional affiliations.

Copyright: (C) 2021 by the authors. Licensee MDPI, Basel, Switzerland. This article is an open access article distributed under the terms and conditions of the Creative Commons Attribution (CC BY) license (https:// creativecommons.org/licenses/by/ $4.0 /)$.
Abstract: It is of great significance to study the effect of solid contents (SC), binder-to-tailings (b/t) ratio, types and dosage of fly ash (FA) on the viscosity $(V)$ and uniaxial compressive strength (UCS) of backfill. It can improve filling efficiency and reduce filling costs to understand the relationship between $\mathrm{SC}, \mathrm{b} / \mathrm{t}$ ratio, FA dosage and viscosity, and UCS of backfill. Consequently, this paper carried out uniaxial compression tests and rheological tests on five different types of backfill specimens. Experimental results indicate that, with the increase of SC, the viscosity and UCS of all backfill samples increases as a power function. With the decrease of $b / t$ ratio, the viscosity and UCS of all backfill samples decreases as an exponential function. The coupling effect of $\mathrm{SC}$ and $\mathrm{b} / \mathrm{t}$ ratio has a great influence on the viscosity and UCS of backfill samples. The relationship between $S C, b / t$ ratio and viscosity, and UCS is a quadratic polynomial function. The order of the viscosity of the backfill slurry is: pure tailings < backfill slurry mixed with Ordinary Portland Cement (OPC) < backfill slurry mixed with FA1 < backfill slurry mixed with FA2. The higher the FA dosage, the greater the viscosity. The order of the UCS of backfill is: backfill with OPC > backfill with FA1 > backfill with FA2. The higher the FA dosage, the smaller the UCS. The UCS of all backfill samples increased with the increase of curing time (CT). The relations between the viscosity and UCS of backfill present the positively linear functions. It is feasible to use viscosity to predict the UCS of backfill, and the error between the UCS predicted value and the test value is mostly controlled within $10 \%$. Ultimately, the findings of the experimental work will provide a scientific reference for the mine to design the strength of the backfill.

Keywords: cemented tailings backfill (CTB); viscosity; uniaxial compressive strength (UCS); strength predicted

\section{Introduction}

At present, underground mining is the main way for humans to obtain metal mineral resources [1,2]. Usually, the ore is separated from the rock by blasting or mechanical cutting to form goaf [3]; after that, useful metal elements are extracted through crushing, grinding, flotation and other processes, and a large number of tailings wastes are formed, the special tailings ponds are needed to store the tailings [4]. If not treated in a timely manner, these tailings will cause serious land pollution, water pollution, and even lead to serious dam break accidents [5,6]. At the same time, if the goaf formed by underground mining is not backfilled, in time this may lead to the collapse of surrounding rocks, induce surface deformation, and seriously threaten the safety of underground workers and equipment $[7,8]$. In order to solve the above problems, a filling method arose at a historic moment $[9,10]$; the tailings are filled to the underground goaf after certain treatment in this method [11,12], and by the filling method, can eliminate the surface subsidence, improve mine safety, increase productivity, create a safe working environment, and provide a reasonable use of tailings, achieving the goal of recycling [13-15]. 
At present, cemented tailings backfill has become the main method for goaf filling [16-18]. First, the tailing slurry is dehydrated to achieve a concentration of $60 \% \sim 75 \%$ [19], and then, according to the design ratio, it is mixed and stirred with a binder to form a cementing filling slurry. The formed cemented filling slurry is usually transported to the underground goaf by gravity or pump [20-22], when it enters the goaf, the filling slurry will gradually hydrate, solidify and produce strength to support the surrounding rock [23-25]. Therefore, the fluidity and strength after curing of filling slurry are the two key contents of the technology; viscosity is an important parameter to characterize the fluidity and workability of the slurry [26-28] and uniaxial compressive strength is one of the key parameters for filling slurry ratio design $[29,30]$. Many scholars have carried out a lot of research on slurry viscosity, strength characteristics and influencing factors. Studies mainly focus on the factors of tailings characteristics (type, grade, concentration, $\mathrm{Ph}$, etc.) [31-34], curing conditions (curing humidity, temperature, time, stratification, etc.) [35-38], gelled material (type, particle size, composition, etc.) [39-42] and admixture (flocculating agent, water reducing agent, fiber, etc.) [43-45] on the influence law of the fluidity, the viscosity and the backfill uniaxial compressive strength. Studies have shown that the particle sizes of tailings and binder have significant influences on the fluidity and compressive strength, within a certain range of particle sizes, and cemented tailings backfill (CTB) with fine particle sizes shows higher yield stress but lower viscosity [46]. Generally, in practical engineering, in order to ensure the filling effect of goaf, a standard sample shall be prepared before filling, and a mechanical test shall be carried out after curing for 3, 7, and 28d, which requires a long time, complicated technology and many interference factors [47-50]. The viscosity test is more simple, timely and can get the results quickly. Previous studies have shown that the compressive strength and viscosity are closely related to the properties of tailings and binder [31-37,40-45] if the compressive strength can be predicted by viscosity, it is of great significance for practical engineering. However, the relationship between viscosity and compressive strength is still less studied.

The type and amount of binder not only affect the properties of backfill, but also have an important impact on the economy. At present, ordinary Portland cement is the most commonly used binder, although ordinary Portland cement has many advantages, its cost is high, accounting for $60-75 \%$ of the whole filling cost [51]. Therefore, the search for substitutes for Portland cement has become a research hotspot in recent years, among which fly ash is one of the most commonly used substitutes for ordinary Portland cement [52-54]. Many researchers around the world have studied the partial replacement of OPC by fly ash; however, due to the different physical and chemical properties of tailings in different mines, these properties directly affect the mechanical properties and strength development of filling materials. In particular, fly ash particle size plays a major role in the fluidity and strength development of filler slurry [55-57].

In this paper, the tailings of an iron mine in China are selected as the experimental objects, OPC and two types of FA replace part of OPC are used as the binder, the influence pattern of different factors on the viscosity and compressive strength is studied by using the control variable method, and the quantitative function formula is established. On this basis, the relationship between viscosity and compressive strength is studied, and then the strength prediction formula of backfill based on viscosity is proposed. The research results of this paper are of great significance for cementing backfill design, cost control, and strength prediction.

\section{Materials and Methods}

\subsection{Experimental Materials and Characteristics}

The tailings of this experiment come from an iron mine in China. SA-CP3 equipment was used to measure the particle size of tailings, and the particle size distribution curve of tailings is shown in Figure 1. The tailings of $\mathrm{d} 10=25.07 \mu \mathrm{m}, \mathrm{d} 50=122.08 \mu \mathrm{m}$, and $\mathrm{d} 90=288.60 \mu \mathrm{m}$. The results of the particle size distribution of tailings show that the grading degree is good. 


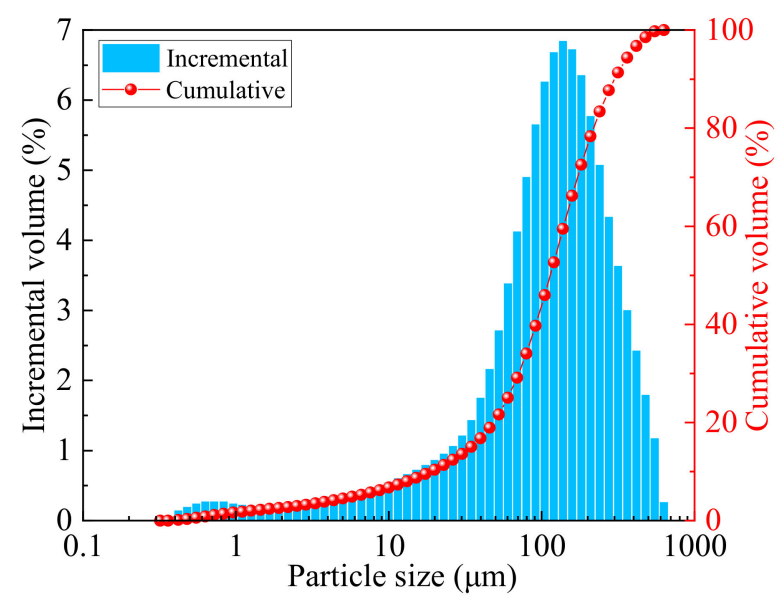

Figure 1. Incremental and cumulative particle size distribution (PSD) curves of tailings.

In China, the price of cement is $350-400 ¥ / \mathrm{t}$, and the cost of cement accounts for $70-80 \%$ of the whole filling cost. Considering the high cost of cement, the mine adopts the fly ash with a lower price to replace part of the cement to reduce the filling cost. In order to be consistent with the actual filling of the mine, three kinds of cementitious agents were used in this test, which is OPC, fly ash 1 (FA1), and fly ash 2 (FA2). The physical and chemical properties of OPC are shown in the literature [26]. The main physical properties of tailings, FA1, and FA2 were measured according to the geotechnical test specification [54], and the results are shown in Table 1 . The density and bulk density of FA1 is smaller than that of FA2, but the porosity of FA1 is larger than that of FA2.

Table 1. Physical properties of materials.

\begin{tabular}{cccc}
\hline Materials & Density $\left(\mathbf{g} / \mathbf{c m}^{\mathbf{3}}\right)$ & Bulk Density $\left(\mathbf{g} / \mathbf{c m}^{\mathbf{3}}\right)$ & Porosity $(\mathbf{\%})$ \\
\hline Tailings & 2.67 & 1.65 & 38.20 \\
FA1 & 2.59 & 0.88 & 66.02 \\
FA2 & 3.09 & 1.47 & 52.43 \\
\hline
\end{tabular}

The main chemical components of tailings, FA1, and FA2 are obtained by XRD diffraction phase analysis. The results are shown in Table 2. The main components of tailings are $\mathrm{Ca}$ and $\mathrm{Mg}$, accounting for $24.99 \%$ and $10.30 \%$, respectively. The main components of FA1 are $\mathrm{Si}, \mathrm{Fe}$, and $\mathrm{Al}$, accounting for $16.19 \%, 15.7 \%$, and $13.2 \%$, respectively. The main components of FA2 are $\mathrm{Ca}$ and $\mathrm{Si}$, accounting for $35.20 \%$ and $16.35 \%$, respectively.

Table 2. Chemical composition of materials.

\begin{tabular}{cccc}
\hline Composition & Tailings & FA1 & FA2 \\
\hline $\mathrm{K}$ & $0.02 \%$ & $0.10 \%$ & $0.97 \%$ \\
$\mathrm{Na}$ & $0.09 \%$ & $0.11 \%$ & $0.33 \%$ \\
$\mathrm{Si}$ & $1.55 \%$ & $16.19 \%$ & $16.35 \%$ \\
$\mathrm{Al}$ & $/$ & $13.20 \%$ & $2.40 \%$ \\
$\mathrm{Ca}$ & $24.99 \%$ & $1.40 \%$ & $35.20 \%$ \\
$\mathrm{Fe}$ & $0.19 \%$ & $15.70 \%$ & $0.20 \%$ \\
$\mathrm{Mg}$ & $10.30 \%$ & $0.50 \%$ & $1.10 \%$ \\
$\mathrm{~Pb}$ & $0.05 \%$ & $<0.05 \%$ & $0.06 \%$ \\
$\mathrm{Mn}$ & $0.04 \%$ & $<0.05 \%$ & $0.05 \%$ \\
$\mathrm{~S}$ & $<0.05 \%$ & $/$ & $/$ \\
\hline
\end{tabular}

The mine uses tap water as the mixing water. The main components of tap water in different places are not much different. It is more convenient to use laboratory tap water to carry out the test and there will be no big error in the test result. 


\subsection{Experiment Scheme Design}

Five types of backfill were designed in this experiment. CTB: Cemented tailings backfill, and all of the binder is OPC. CFTB1-1: Cemented fly ash tailings backfill, and the binder is OPC and FA1, in which OPC: FA1 $=0.8: 0.2$. CFTB1-2: Cemented fly ash tailings backfill, and the binder is OPC and FA1, in which OPC: FA1 = 0.5:0.5. CFTB2-1: Cemented fly ash tailings backfill, and the binder is OPC and FA2, in which OPC: FA2 $=0.8: 0.2$ CFTB2-2: Cemented fly ash tailings backfill, and the binder is OPC and FA2, in which OPC: FA2 $=0.5: 0.5$. All types of backfill samples have solid content (SC) of $66 \%, 68 \%, 70 \%$, and $72 \%$ and $b / t$ ratios of 1:4, 1:6, 1:8, 1:10, and 1:12. The test scheme is shown in Table 3 .

Table 3. Test scheme of different types of backfill.

\begin{tabular}{cccc}
\hline Sample Type & Binder & OPC: FA & Aggregate \\
\hline CTB & OPC & $/$ & \\
CFTB1-1 & OPC + FA1 & $0.8: 0.2$ & \\
CFTB1-2 & & $0.5: 0.5$ & Tailings \\
CFTB2-1 & OPC + FA2 & $0.8: 0.2$ & \\
CFTB2-2 & & $0.5: 0.5$ & \\
\hline
\end{tabular}

\subsection{Viscosity Testing}

Viscosity is one of the important rheological parameters of backfill. To investigate the viscosity of backfill samples at different $\mathrm{SC}$ and $\mathrm{b} / \mathrm{t}$ ratios, a Brookfield $\mathrm{R} / \mathrm{S}+\mathrm{SST}$ (soft solid tester) rotational rheometer with a vane geometry was used with optional Rheo3000 software (AMETEK Brookfield, Middleborough, MA, USA), as shown in Figure 2. The tailings, cement, fly ash, and water were weighed according to the requirements of the test ratio. First, the tailings and binder were poured into the glass and mixed well, then water was added to mix. The mixing time should not be less than $5 \mathrm{~min}$. Finally, the well-stirred slurry was placed under the viscometer, and the computer program was started to carry out the viscosity test. After the test, the viscosity result is automatically displayed on the screen.

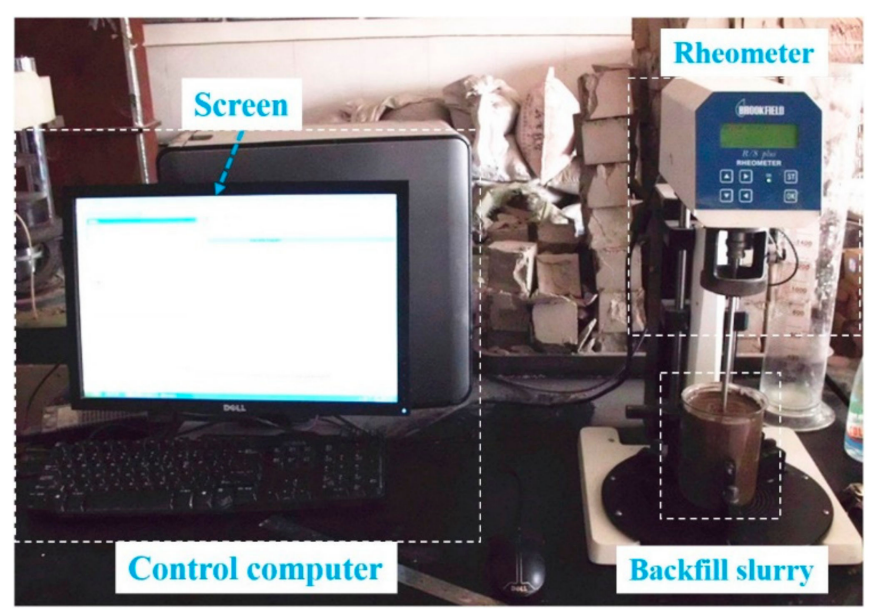

Figure 2. Viscosity testing apparatus of backfill slurry mixes.

\subsection{Uniaxial Compressive Testing}

The uniaxial compressive strength of backfill is one of the most important mechanical parameters. In this study, the DONGCE microcomputer-controlled servo test system (Figure 3) was used to carry out the uniaxial compressive test on backfill with SC of $66 \%$, $68 \%, 70 \%$, and $72 \%$, curing time (CT) of $7 \mathrm{~d}, 14 \mathrm{~d}$, and $28 \mathrm{~d}$, and b/t ratio of 1:4, 1:6, 1:8, 1:10, and 1:12. 


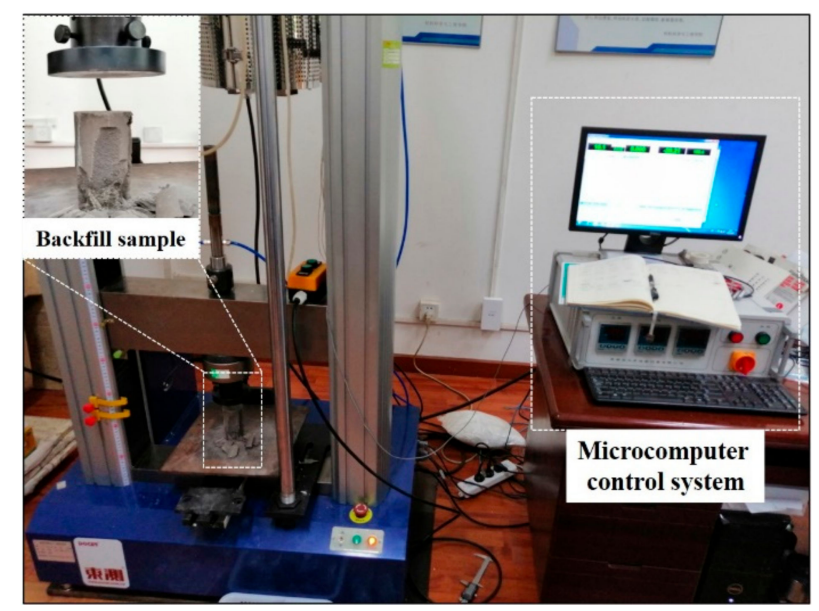

Figure 3. Uniaxial compression test system.

\section{Results and Discussion}

3.1. Viscosity Results of Different Types of Backfill Samples

Viscosity is one of the important rheological parameters of the backfill. Backfill viscosity is closely related to the $\mathrm{b} / \mathrm{t}$ ratio, $\mathrm{SC}$, and binder type. An in-depth understanding of the viscosity characteristics of the backfill is essential for the rational arrangement of the filling pipeline, the reasonable design of the pumping pressure, and the prediction of the settlement behavior of the backfill slurry. Table 4 shows the viscosity results of different types of backfill samples.

Table 4. Viscosity results of different samples.

\begin{tabular}{|c|c|c|c|c|c|c|c|}
\hline \multirow{2}{*}{$\begin{array}{c}\text { Binder-Tailings } \\
\text { Ratio (b/t) }\end{array}$} & \multirow{2}{*}{$\begin{array}{l}\text { Solid Content } \\
\text { (SC) } / \%\end{array}$} & \multicolumn{6}{|c|}{ Sample Type } \\
\hline & & СТВ & CFTB1-1 & CFTB1-2 & CFTB2-1 & CFTB2-2 & Tailings \\
\hline $1: 4$ & \multirow{5}{*}{66} & 810 & 836 & 978 & 878 & 1033 & \multirow{5}{*}{512} \\
\hline $1: 6$ & & 772 & 794 & 925 & 811 & 966 & \\
\hline $1: 8$ & & 693 & 712 & 862 & 760 & 915 & \\
\hline $1: 10$ & & 625 & 655 & 824 & 724 & 865 & \\
\hline $1: 12$ & & 563 & 596 & 787 & 679 & 803 & \\
\hline $1: 4$ & \multirow{5}{*}{68} & 1123 & 1117 & 1213 & 1158 & 1311 & \multirow{5}{*}{629} \\
\hline $1: 6$ & & 967 & 994 & 1094 & 989 & 1138 & \\
\hline $1: 8$ & & 848 & 875 & 1005 & 911 & 1090 & \\
\hline $1: 10$ & & 765 & 803 & 956 & 875 & 998 & \\
\hline $1: 12$ & & 701 & 729 & 889 & 786 & 904 & \\
\hline $1: 4$ & \multirow{5}{*}{70} & 1432 & 1383 & 1503 & 1425 & 1652 & \multirow{5}{*}{715} \\
\hline $1: 6$ & & 1230 & 1201 & 1343 & 1244 & 1388 & \\
\hline $1: 8$ & & 1021 & 1090 & 1180 & 1145 & 1287 & \\
\hline $1: 10$ & & 881 & 965 & 1095 & 1032 & 1163 & \\
\hline $1: 12$ & & 793 & 894 & 997 & 865 & 1022 & \\
\hline $1: 4$ & \multirow{5}{*}{72} & 1675 & 1698 & 1825 & 1733 & 1998 & \multirow{5}{*}{805} \\
\hline $1: 6$ & & 1432 & 1467 & 1654 & 1522 & 1644 & \\
\hline $1: 8$ & & 1232 & 1392 & 1493 & 1423 & 1532 & \\
\hline $1: 10$ & & 1032 & 1188 & 1336 & 1232 & 1349 & \\
\hline $1: 12$ & & 892 & 1083 & 1247 & 1131 & 1254 & \\
\hline
\end{tabular}

\subsubsection{Viscosity Analysis of Different Type Backfill Samples}

In order to accurately obtain the relationship between the backfill's viscosity, SC, and $b / t$ ratio, the control variable method is adopted, and only one variable is changed while other parameters are kept unchanged. Figure 4 shows the columnar relationship between the different types of backfills' viscosity, $\mathrm{SC}$, and $\mathrm{b} / \mathrm{t}$ ratio. 

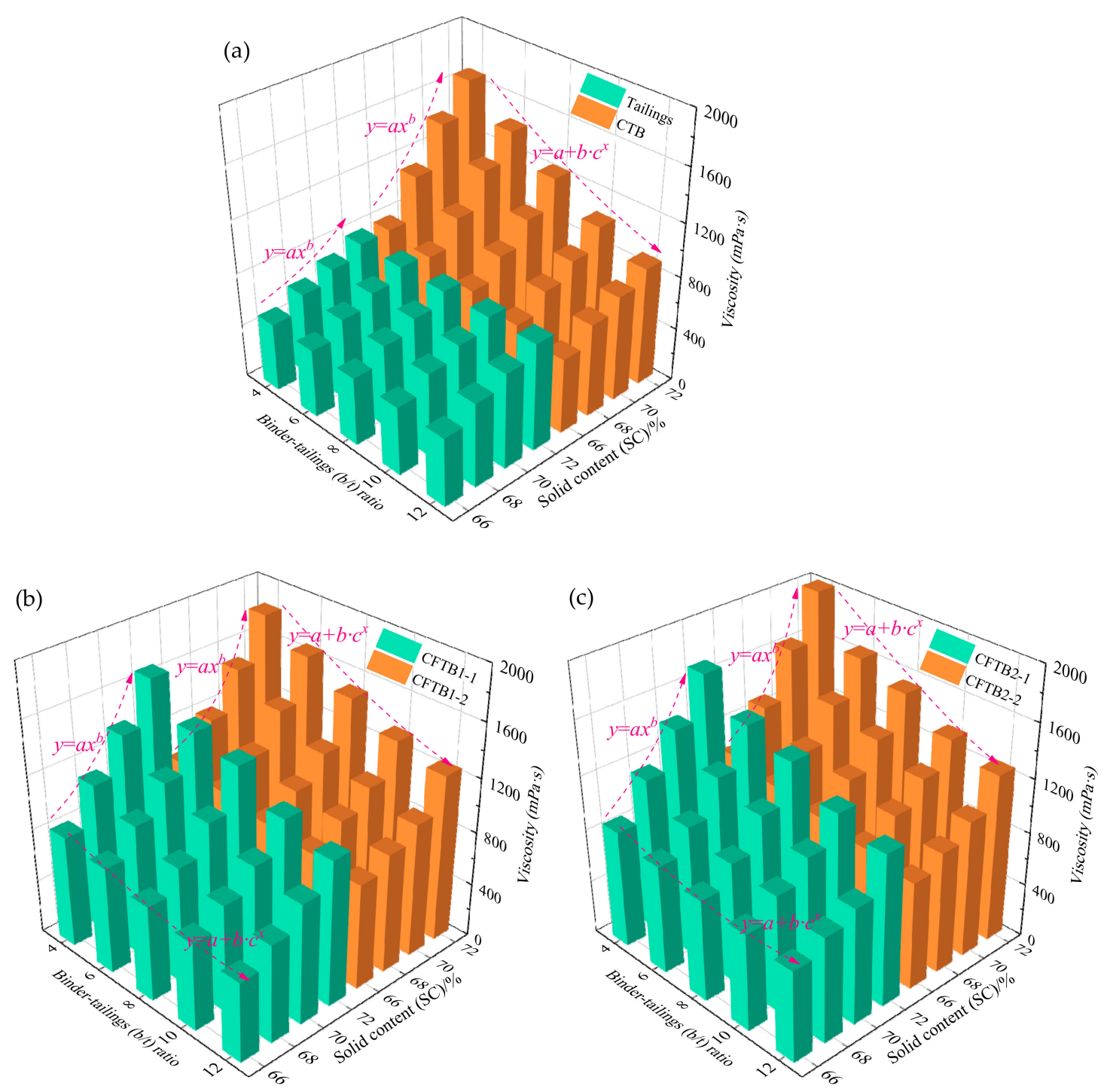

Figure 4. Viscosity results of different backfill samples: (a) cemented tailings backfill (CTB) and tailings; (b) CFTB1; (c) CFTB2.

Figure 4a shows the columnar relationship between the viscosity of pure tailings sample and SC, and the columnar relationship between the viscosity of CTB sample, SC, and $b / t$ ratio. Observing the green cube column, the viscosity of pure tailings sample increases with the increase of SC as a power function. When SC is $66 \%$, the viscosity is $512 \mathrm{mPa} \cdot \mathrm{s}$; when SC is increased to $68 \%$, the viscosity increases to $629 \mathrm{mPa} \cdot \mathrm{s}$, the growth rate is $22.9 \%$; when SC increases to $70 \%$ and $72 \%$, respectively, the viscosity increased to 715 and $805 \mathrm{mPa} \cdot \mathrm{s}$, respectively, the growth rate was $39.6 \%$ and $57.2 \%$. Observing the yellow cube column, the viscosity of the CTB sample increases as the SC increases with a power function, and decreases as the $b / t$ ratio decreases with an exponential function. Taking $a b / t$ ratio of 1:4 as an example, when the SC is $66 \%$, the CTB viscosity is $810 \mathrm{mPa} \cdot \mathrm{s}$; when the SC is increased to $68 \%, 70 \%$, and $72 \%$, respectively, the CTB viscosity is increased to 1123,1432 , and $1675 \mathrm{mPa} \cdot \mathrm{s}$, respectively, with growth rates of $38.6 \%, 76.8 \%$, and $106.8 \%$, respectively. Taking SC of $68 \%$ as an example, when the $\mathrm{b} / \mathrm{t}$ ratio is $1: 4$, the CTB viscosity is $1123 \mathrm{mPa} \cdot \mathrm{s}$; when the $\mathrm{b} / \mathrm{t}$ ratio is reduced to $1: 6$, the CTB viscosity is reduced to $967 \mathrm{mPa} \cdot \mathrm{s}$, the reduction rate is $13.9 \%$; when the $b / t$ ratio is reduced to $1: 8,1: 10$, and $1: 12$, respectively, the CTB viscosity is reduced to 848,765 , and $701 \mathrm{mPa} \cdot \mathrm{s}$, respectively, the reduction rate is $24.5 \%$, $31.9 \%$, and $37.7 \%$, respectively. 
Figure $4 \mathrm{~b}$ shows the columnar relationship between the viscosity of CFTB1-1and CFTB1-2, SC, and b/t ratio. Observing the green cube column, it can be seen that the viscosity of the CFTB1-1 increases as the SC increases with a power function, and as the $\mathrm{b} / \mathrm{t}$ ratio decreases with an exponential function. Keeping the $\mathrm{b} / \mathrm{t}$ ratio of 1:4 constant, when SC is $66 \%$, CFTB1-1 viscosity is $836 \mathrm{mPa} \cdot \mathrm{s}$; with an increase in SC to $68 \%, 70 \%$, and $72 \%$, respectively, CFTB1-1 viscosity increases to 1117,1383 , and $1698 \mathrm{mPa} \cdot \mathrm{s}$, respectively, with growth rates of $30.4 \%, 65.4 \%$, and $103.1 \%$, respectively. Keeping the SC of $68 \%$ constant, when the $\mathrm{b} / \mathrm{t}$ ratio is $1: 4$, the CFTB1-1 viscosity is $1117 \mathrm{mPa} \cdot \mathrm{s}$; when the $\mathrm{b} / \mathrm{t}$ ratio is reduced to $1: 6,1: 8,1: 10$, and $1: 12$, respectively, the viscosity of CFTB1-1 is reduced to $994,875,803$ and $729 \mathrm{mPa} \cdot \mathrm{s}$, respectively, and the reduction rate is $11.0 \%, 21.7 \%$, $28.1 \%$, and $34.7 \%$, respectively. The yellow cube column shows that the viscosity of the CFTB1-2 increases with the increase of SC as a power function, and with the decrease of the $\mathrm{b} / \mathrm{t}$ ratio, it decreases as an exponential function. When SC increases from $66 \%$ to $72 \%$ at $\mathrm{a} b / \mathrm{t}$ ratio of $1: 4$, the CFTB1-2 viscosity growth rate is $86.6 \%$; the CFTB1-2 viscosity growth rate is $78.8 \%$ at $\mathrm{a} b / \mathrm{t}$ ratio of $1: 6$. When SC increases from $66 \%$ to $72 \%$ at a b/t ratio of $1: 8,1: 10$, and $1: 12$, respectively, the CFTB1-2 viscosity growth rate is $73.2 \%, 62.1 \%$, and $58.4 \%$, respectively. When the $\mathrm{b} / \mathrm{t}$ ratio is reduced from $1: 4$ to $1: 12$ at SC of $66 \%$, the CFTB1-2 viscosity reduction is $19.5 \%$; When the $b / t$ ratio is reduced from $1: 4$ to $1: 12$ at SC of $68 \%, 70 \%$, and $72 \%$, respectively, the viscosity reduction rate of CFTB1-2 is $26.7 \%$, $33.7 \%$, and $31.7 \%$, respectively.

Figure $4 \mathrm{c}$ shows the columnar relationship between the viscosity of CFTB2-1 and CFTB2-2, SC, and the $b / t$ ratio. The green cubes show the relationship between the viscosity of the CFTB2-1, SC, and $b / t$ ratio. The viscosity of CFTB2-1 increases as the $\mathrm{SC}$ increases with a power function, and decreases as the $b / t$ ratio decreases with an exponential function. When SC increased from $66 \%$ to $72 \%$ at $\mathrm{b} / \mathrm{t}$ ratio of $1: 4, \mathrm{CFTB} 2-1$ viscosity growth rate is $97.4 \%$. When SC increased from $66 \%$ to $72 \%$ at b/t ratio of $1: 6$, $1: 8,1: 10$, and 1:12, respectively, CFTB2- 1 viscosity growth rate is $87.7 \%, 87.2 \%, 70.2 \%$ and $66.6 \%$, respectively. When $\mathrm{b} / \mathrm{t}$ ratio decreased from $1: 4$ to $1: 12$ at SC of $66 \%, 68 \%, 70 \%$, and $72 \%$, respectively, CFTB2-1 viscosity growth rate is $22.7 \%, 32.1 \%, 39.3 \%$, and $34.7 \%$, respectively. The yellow cubes show the relationship between the viscosity of the CFTB2-2, $\mathrm{SC}$, and $\mathrm{b} / \mathrm{t}$ ratio. The viscosity of CFTB2-2 increases as the SC increases with a power function, and decreases as the $b / t$ ratio decreases with an exponential function. When SC increased from $66 \%$ to $72 \%$ at $\mathrm{b} / \mathrm{t}$ ratio of $1: 4,1: 6,1: 8,1: 10$, and $1: 12$, respectively, CFTB2-2 viscosity growth rate is $48.3 \%, 70.2 \%, 67.4 \%, 56.0 \%$, and $56.2 \%$, respectively. When the $\mathrm{b} / \mathrm{t}$ ratio decreased from $1: 4$ to $1: 12$ at SC of $66 \%, 68 \%, 70 \%$, and $72 \%$, respectively, CFTB2-2 viscosity growth rate is $22.2 \%, 31.0 \%, 38.1 \%$, and $37.2 \%$, respectively.

According to the above results, the viscosity of the backfill sample increases with the increase of SC, and decreases with the decrease of the b/t ratio. As the SC increases, the solid particle content in the backfill slurry increases, and the friction action between particle and particle, and particle and the tube wall increases, resulting in an increase in slurry viscosity. As the $b / t$ ratio is reduced, the binder content in the backfill slurry is reduced, the C-S-H gel produced after the hydration reaction decreases, and the binding force and friction action between the particle and particle is reduced, resulting in a decrease in viscosity.

In order to analyze the effect of the coupling effect of SC and b/t ratio on the viscosity of the backfill, the SC and b/t ratio are used as the abscissa and viscosity as the ordinate to obtain a three-dimensional scatter diagram between the SC, b/t ratio, and viscosity, and the results are shown in Figure 5. It can be seen intuitively from Figure 5 that the viscosity of backfill has an important correlation with both the SC and $b / t$ ratio. The viscosity increases as SC increases and decreases as the $b / t$ ratio decreases. A quadratic polynomial is used to fit and analyze the viscosity results. It is found that the viscosity of the backfill had a good quadratic polynomial function relationship with $\mathrm{SC}$ and $\mathrm{b} / \mathrm{t}$ ratio. The fitted multiple correlation coefficients $R^{2}$ are all greater than 0.98 , and the average fitted multiple correlation coefficient $R^{2}$ is 0.9915 , and the fitting results are shown in Table 5. 

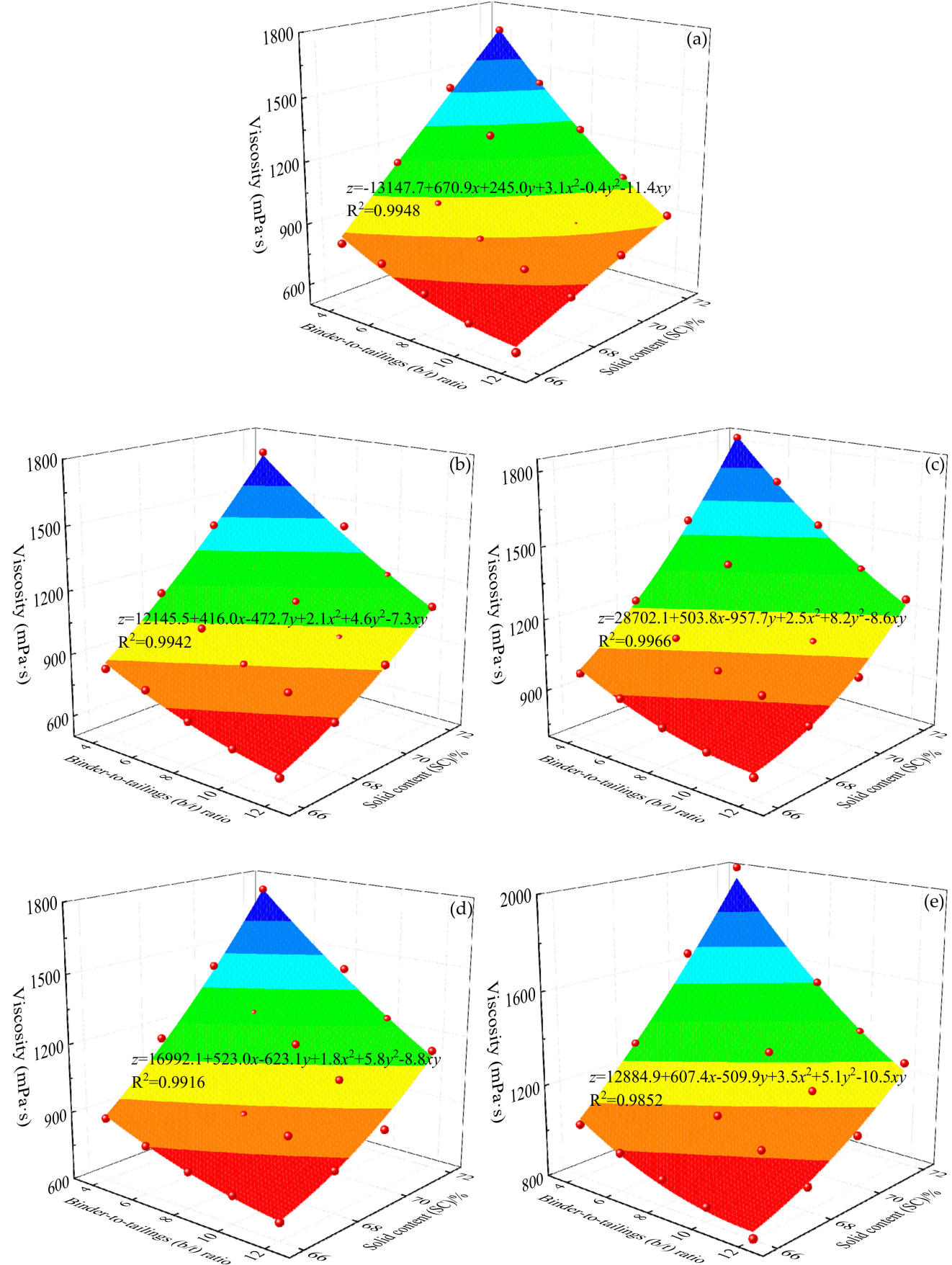

Figure 5. Coupling effects of solid contents (SC) and b/t ratio on the viscosity of different type backfill: (a) CTB; (b) CFTB1-1; (c) CFTB1-2; (d) CFTB2-1; (e) CFTB2-2.

Table 5. Fitting relationship between SC, b/t ratio and viscosity of backfill samples.

\begin{tabular}{ccc}
\hline Sample Type & Fitting Relationship & $\mathbf{R}^{\mathbf{2}}$ \\
\hline CTB & $\mathrm{V}=13147.7+670.9 \mathrm{x}+245.0 \mathrm{y}+3.1 \mathrm{x}^{2}-0.4 \mathrm{y}^{2}-11.4 \mathrm{xy}$ & 0.9948 \\
CFTB1-1 & $\mathrm{V}=12145.5+416.0 \mathrm{x}-472.7 \mathrm{y}+2.1 \mathrm{x}^{2}+4.6 \mathrm{y}^{2}-7.3 \mathrm{xy}$ & 0.9942 \\
CFTB1-2 & $\mathrm{V}=28702.1+503.8 \mathrm{x}-957.7 \mathrm{y}+2.5 \mathrm{x}^{2}+8.2 \mathrm{y}^{2}-8.6 \mathrm{xy}$ & 0.9966 \\
CFTB2-1 & $\mathrm{V}=16992.1+523.0 \mathrm{x}-623.1 \mathrm{y}+1.8 \mathrm{x}^{2}+5.8 \mathrm{y}^{2}-8.8 \mathrm{xy}$ & 0.9916 \\
CFTB2-2 & $\mathrm{V}=12884.9+607.4 \mathrm{x}-509.9 \mathrm{y}+3.5 \mathrm{x}^{2}+5.1 \mathrm{y}^{2}-10.5 \mathrm{xy}$ & 0.9852 \\
\hline
\end{tabular}




\subsubsection{Comparative Analysis of Viscosity of Different Types of Backfill Samples}

In order to analyze the effect of the content and type of binder on the viscosity of the backfill slurry, the viscosity results of different types of backfill slurry with $a b / t$ ratio of 1:8 are selected for comparative analysis. The results are shown in Figure 6.
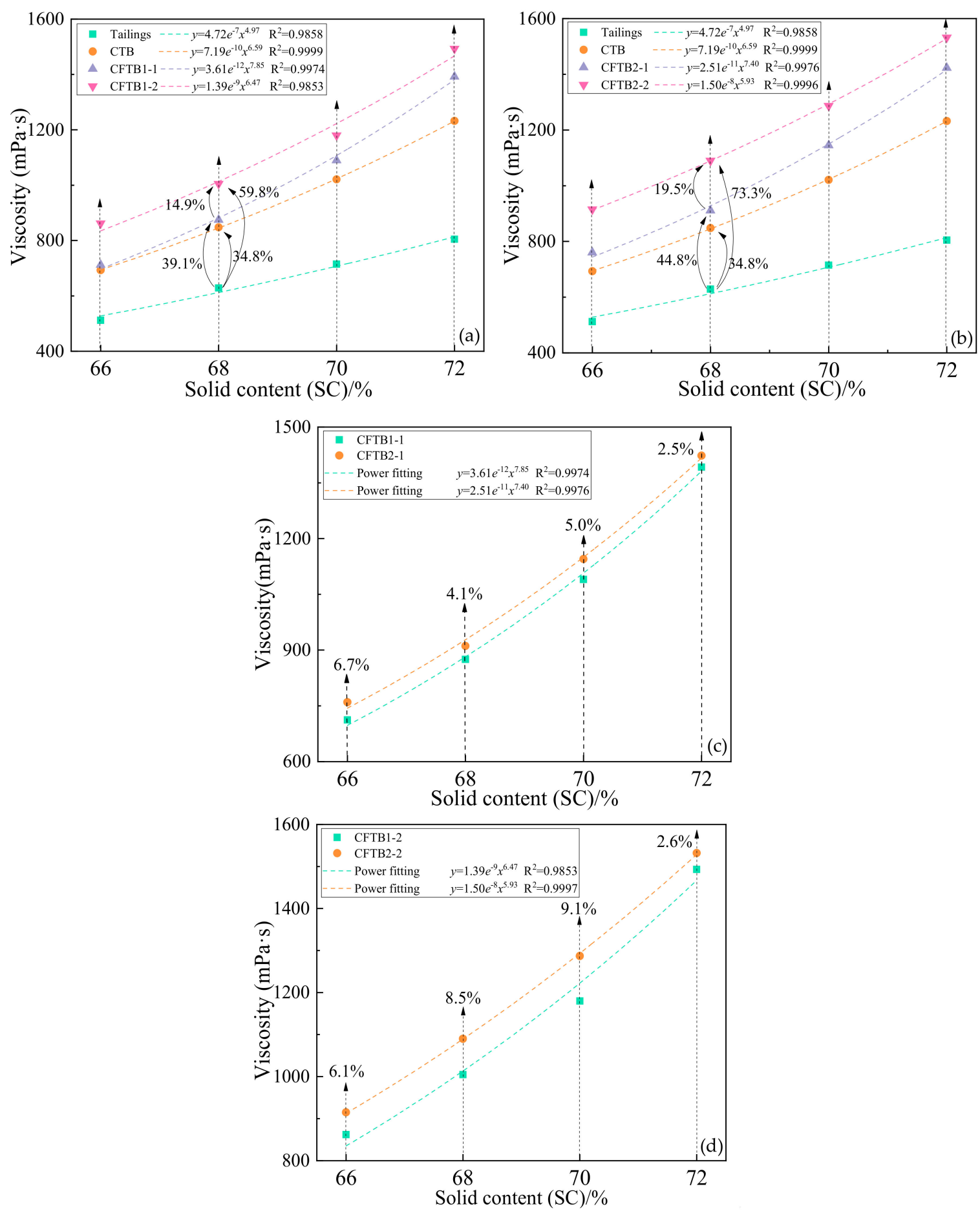

Figure 6. Comparison of the viscosity of different types of backfill slurry with a b/t ratio of 1:8. (a) CFTB1 and CTB; (b) CFTB2 and CTB; (c) CFTB2-1 and CFTB1-1; (d) CFTB2-2 and CFTB1-2.

Figure 6a shows the comparison results of the viscosity of tailings, CTB, CFTB1-1, and CFTB1-2. It can be seen from the vertical direction, the viscosity of the backfill sample is: Tailing $<$ CTB $<$ CFTB1-1 $<$ CFTB1-2. The viscosity of the all-backfill slurry containing 
binder is higher than that of the pure tailings slurry. When SC is $68 \%$, compared with the pure tailings slurry, CTB viscosity increases by about $34.8 \%$, CFTB1- 1 viscosity increases by about $39.1 \%$, and CFTB1-2 viscosity increases by about $59.8 \%$. Comparing CTB and CFTB1, it can be seen that the viscosity of the backfill slurry increases with the addition of FA1, and the more FA1 is added, the greater the increase in viscosity. Also taking SC of $68 \%$ as an example, when the FA1 dosage is $20 \%$, the viscosity increases by about $3.2 \%$, and when the FA1 dosage is $50 \%$, the viscosity increases by about $14.9 \%$.

Figure $6 \mathrm{~b}$ shows the comparison results of the viscosity of tailings, CTB, CFTB2-1 and CFTB2-2. It can be seen from Figure $6 \mathrm{~b}$ that the viscosity of the backfill slurry is: Tailing $<$ CTB $<$ CFTB2-1 $<$ CFTB2-2. This result shows that after the binder is added to the tailings slurry, the viscosity of the slurry increases significantly. Taking $68 \%$ as an example, compared with pure tailings slurry, CTB viscosity increased by approximately $34.8 \%$, CFTB2-1 viscosity increased by approximately $44.8 \%$, and CFTB2-2 viscosity increased by approximately $73.3 \%$. Comparing CTB and CFTB2, it can be seen that the viscosity of the backfill slurry increases with the addition of FA2, and the more FA2 is added, the greater the viscosity increase. Also taking SC as $68 \%$ as an example, when the FA2 dosage is $20 \%$, the viscosity increases by about $7.4 \%$, and when the FA2 dosage is $50 \%$, the viscosity increases by about $28.5 \%$.

Figure $6 c, d$ shows the comparison results of the viscosity of the backfill slurry with the same FA content and different FA types. When the FA dosage is the same, the viscosity of the backfill slurry mixed with FA2 is greater than that of FA1. When the FA dosage is $20 \%$ at SC of $66 \%$, the viscosity of CFTB2-1 is increased by $6.7 \%$ compared to the viscosity of CFTB1-1; when the FA dosage is $20 \%$ at SC of $68 \%, 70 \%$, and $72 \%$, respectively, the viscosity increases by $4.1 \%, 5.0 \%$, and $2.2 \%$, respectively. When the FA dosage is $50 \%$ at SC of $66 \%$, the viscosity of CFTB2-2 is increased by $6.1 \%$ compared to the viscosity of CFTB1-2; when the FA dosage is $50 \%$ at SC of $68 \%, 70 \%$, and $72 \%$, respectively, the viscosity increases by $8.5 \%, 9.1 \%$, and $2.6 \%$, respectively.

A comprehensive analysis of the above results shows that the backfill slurry with a binder has a higher viscosity than the slurry without the binder. The backfill slurry with the FA has a higher viscosity than the backfill slurry without the FA. For the same FA dosage, the backfill slurry with the FA2 has a higher viscosity than the backfill slurry with the FA1. For the same FA type, the higher the FA dosage, the higher the viscosity of the backfill slurry.

\subsection{UCS Results of Different Types of Backfills Samples}

\subsubsection{UCS Analysis of Different Type Backfill Samples}

In order to deeply analyze the influence of $\mathrm{SC}, \mathrm{b} / \mathrm{t}$ ratio, and curing age on the uniaxial compressive strength (UCS) of backfill, the control variable method is adopted to change a single factor while keeping other factors unchanged. Figure 7 shows the UCS results of different types of backfill.

Figure 7a shows the UCS result of CTB with different $S C$, different $b / t$ ratio, and different curing age. Keeping the curing age and the $b / t$ ratio constant, the UCS of CTB increases as the SC increases with a power function. Taking the curing age of $14 \mathrm{~d}$ and the $\mathrm{b} / \mathrm{t}$ ratio of $1: 4$ as an example, when the SC is $66 \%$, the UCS of CTB is $0.622 \mathrm{MPa}$; when the SC increased to $68 \%$, the UCS of CTB is $0.851 \mathrm{MPa}$, the growth rate is $36.8 \%$; when the SC increased to $70 \%$ and $72 \%$, respectively, the UCS of CTB is 1.254 and $1.663 \mathrm{MPa}$, respectively, and the growth rates are $101.6 \%$ and $167.4 \%$, respectively. Keeping the curing age and the SC constant, the UCS of CTB decreases as the $b / t$ ratio decreases with an exponential function. Taking the curing age of $14 \mathrm{~d}$ and the SC of $68 \%$ as an example, when the $\mathrm{b} / \mathrm{t}$ ratio is 1:4, the UCS of CTB is $1.999 \mathrm{MPa}$; when the $\mathrm{b} / \mathrm{t}$ ratio reduced to 1:6, 1:8, 1:10, and 1:12, respectively, the UCS of CTB reduced to $1.235,0.851,0.612$, and $0.401 \mathrm{MPa}$, respectively, the reduction rates are $38.2 \%, 57.4 \%, 69.4 \%$, and $79.9 \%$, respectively. Keeping the SC and the $\mathrm{b} / \mathrm{t}$ ratio constant, the UCS of CTB increases as the curing age increases. Taking the SC of $68 \%$ and the $b / t$ ratio of $1: 8$ as an example, when the curing age is $7 d$, the UCS of 
CTB is $0.348 \mathrm{MPa}$; when the curing age increased to 14 and $28 \mathrm{~d}$, respectively, the UCS of CTB increased to 0.851 and $1.315 \mathrm{MPa}$, respectively, and the growth rates are $144.5 \%$ and $277.9 \%$, respectively.
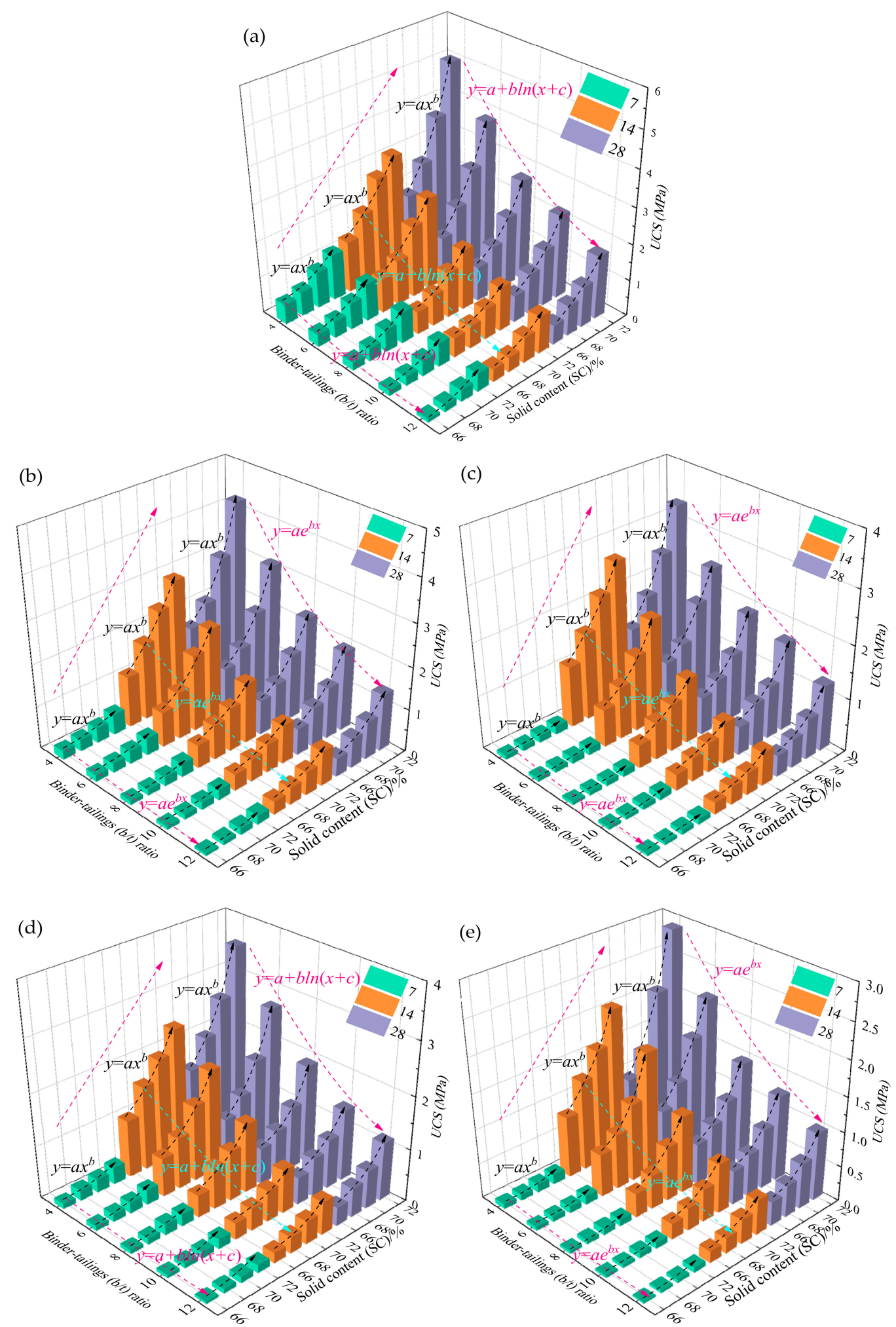

Figure 7. Relation between uniaxial compressive strength (UCS) and effect factors: (a) CTB; (b) CFTB1-1; (c) CFTB1-2; (d) CFTB2-1; (e) CFTB2-2. 
Figure $7 \mathrm{~b}$ shows the columnar relationship between the UCS of CFTB1-1 and SC, $\mathrm{b} / \mathrm{t}$ ratio, and curing age. Keeping the curing age and the $b / t$ ratio constant, the UCS of CFTB1-1 increases as the SC increases with a power function. Taking the curing age of $14 \mathrm{~d}$ and the $b / t$ ratio of $1: 8$ as an example, when SC increased from $66 \%$ to $72 \%$, the UCS of CFTB1-1 reduced from 0.541 to $1.421 \mathrm{MPa}$, the reduction rate is $162.7 \%$. Keeping the curing age and the SC constant, the UCS of CFTB1-1 decreases as the b/t ratio decreases with an exponential function. Taking the curing age of $14 \mathrm{~d}$ and the $\mathrm{SC}$ of $68 \%$ as an example, when the $\mathrm{b} / \mathrm{t}$ ratio reduced from 1:4 to 1:12, the UCS of CFTB1-1 reduced from $1.813 \mathrm{MPa}$ to $0.392 \mathrm{MPa}$, the reduction rate is $78.4 \%$. Keep the SC and the $\mathrm{b} / \mathrm{t}$ ratio constant, the UCS of CFTB1-1 increases as the curing age increases. Taking the SC of $68 \%$ and the $\mathrm{b} / \mathrm{t}$ ratio of 1:8 as an example, when the curing age increased from 7d to 28d, the UCS of CFTB1-1 increased from 0.131 to $1.022 \mathrm{MPa}$, and the growth rate reached $680.2 \%$.

Figure 7c shows the columnar relationship between the UCS of CFTB1-2 and SC, $\mathrm{b} / \mathrm{t}$ ratio, and the curing age. Keeping the curing age and $b / t$ ratio constant, the UCS of CFTB1-2 increases as the SC increases with a power function. Taking the curing age of $14 \mathrm{~d}$ and $\mathrm{b} / \mathrm{t}$ ratio of $1: 8$ as an example, when SC increased from $66 \%$ to $72 \%$, the UCS of CFTB1-2 increased from 0.433 to $1.222 \mathrm{MPa}$, the growth rate is $182.2 \%$. Keep the curing age and the SC constant, the UCS of CFTB1-2 reduced as the $b / t$ ratio reduced with an exponential function. Taking the curing age of $14 \mathrm{~d}$ and SC of $68 \%$ as an example, when the $\mathrm{b} / \mathrm{t}$ ratio decreased from 1:4 to 1:12, the UCS of CFTB1-2 decreased from 1.647 to $0.333 \mathrm{MPa}$, the reduction rate is $79.8 \%$. Keep the SC and the $\mathrm{b} / \mathrm{t}$ ratio constant, the UCS of CFTB1-2 increases as the curing age increases. Taking SC of $68 \%$ and $b / t$ ratio of $1: 8$ as an example, when the curing age increased from $7 \mathrm{~d}$ to $28 \mathrm{~d}$, the UCS of CFTB1-2 increased from 0.074 to $0.894 \mathrm{MPa}$, increases by about 11 times.

Figure 7d,f shows the UCS results of CFTB2-1 and CFTB2-2, respectively. Keeping the curing age and the $b / t$ ratio constant, the UCS of CFTB2-1 and CFTB2-2 increases as the SC increases with a power function. Keep the curing age and the SC constant, the UCS of CFTB2-1 decreases as the $b / t$ ratio decreases with a logarithmic function, the UCS of CFTB2-2 decreases as the $b / t$ ratio decreases with an exponential function. Keep the SC and the $b / t$ ratio constant, the UCS of CFTB2-1 and CFTB2-2 both increases as the curing age increases.

The comprehensive analysis of the above results shows that the UCS of the backfill increases with the increase of $\mathrm{SC}$, decreases with the decrease of the $b / t$ ratio, and increases with the increase of the curing age. As the SC increases, the solid particle content in the backfill slurry increases, porosity inside the backfill decreases after the hydration reaction, and the overall strength of the backfill increases; as the $b / t$ ratio is reduced, the binder particle content in the backfill slurry is reduced, the C-S-H gel produced after the hydration reaction decreases, the overall strength of backfill decreases; as the curing age increases, the hydration reaction between particle and particle inside backfill is sufficient, more C-S-H gel was produced, and the overall strength of the backfill increases.

In order to understand the influence of the coupling factors of the $\mathrm{SC}$ and $\mathrm{b} / \mathrm{t}$ ratio on the UCS of backfill, keep the curing age unchanged, and change the $S C$ and $b / t$ ratio to obtain the three-dimensional scattered diagram between the $\mathrm{SC}, \mathrm{b} / \mathrm{t}$ ratio, and UCS, as shown in Figure 8. It can be seen more intuitively from Figure 8 that the UCS of backfill increases with increasing $\mathrm{SC}$ and decreases with decreasing $\mathrm{b} / \mathrm{t}$ ratio. A three-dimensional surface fitting is carried out for the three-dimensional scatter diagram, and the fitting results are shown in Table 6. It can be seen from Table 6 that there is a good quadratic polynomial function relationship between the $\mathrm{SC}, \mathrm{b} / \mathrm{t}$ ratio, and $\mathrm{UCS}$ of the backfill. The fitting multiple correlation coefficient $R^{2}$ is greater than 0.97 , and the average multiple correlation coefficient $R^{2}$ is as high as 0.9871 . 

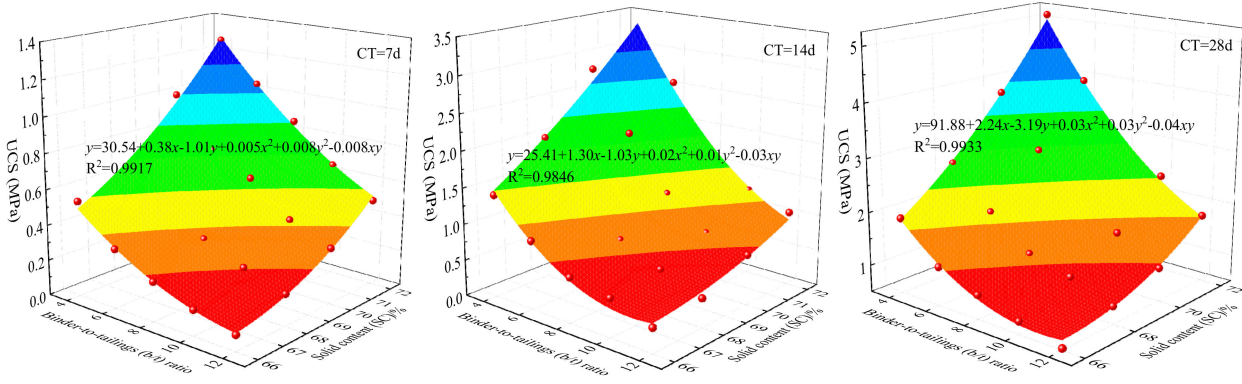

(a) CTB
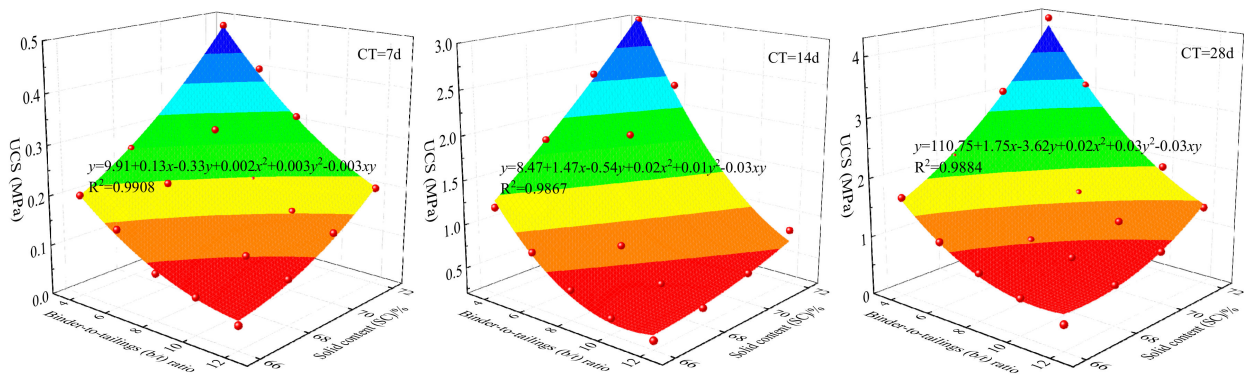

(b) CFTB1-1
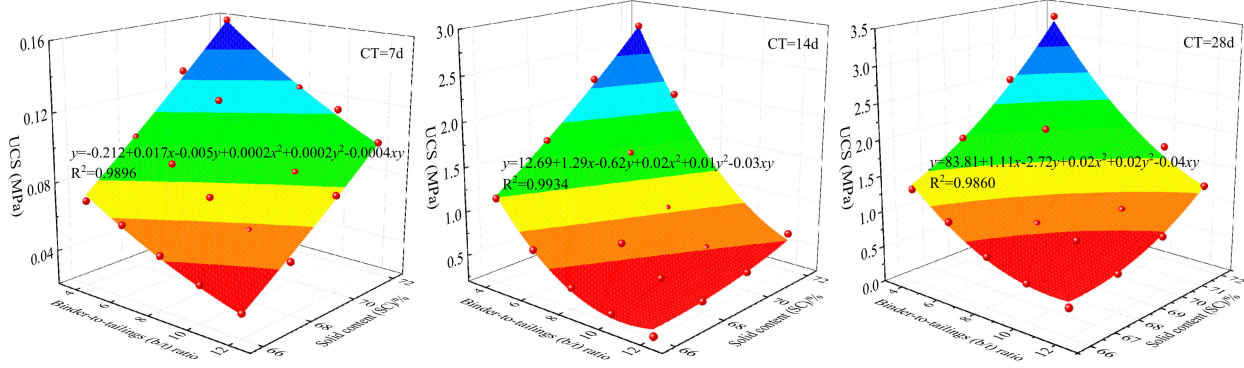

(c) CFTB1-2
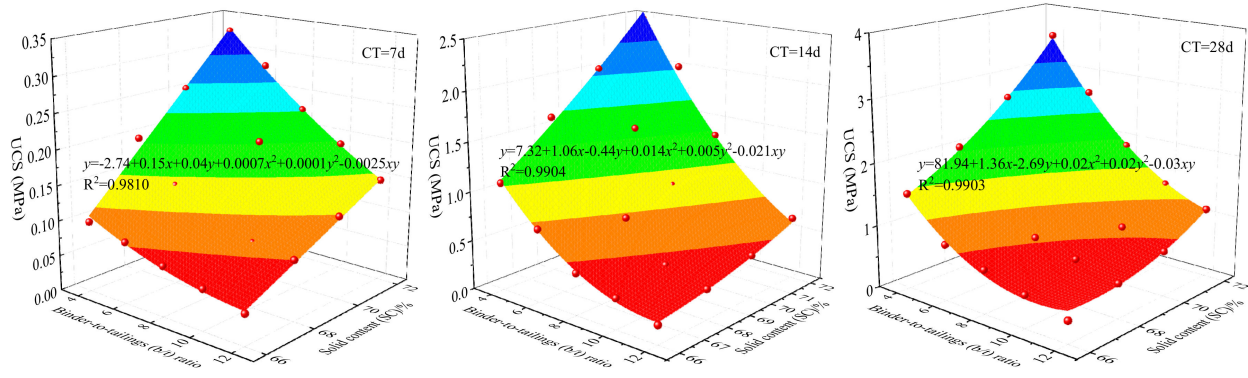

(d) CFTB2-1
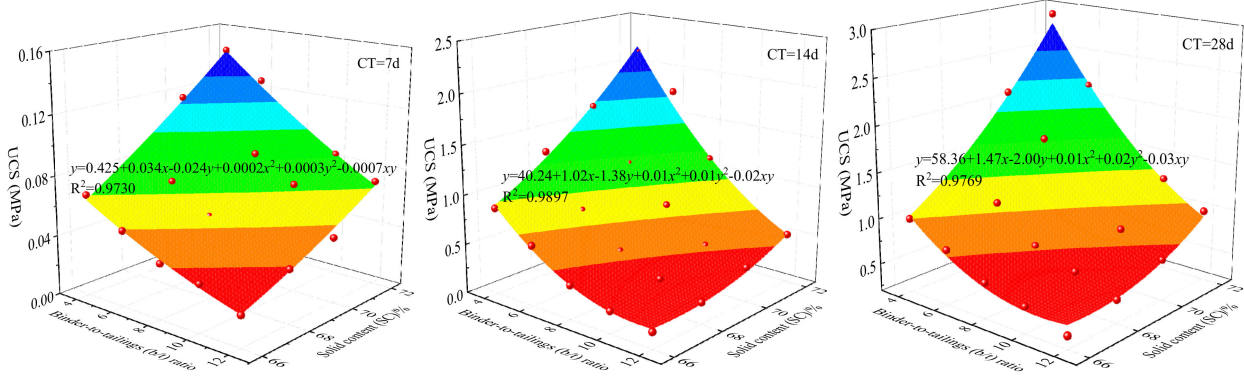

(e) CFTB2-2

Figure 8. Coupling effects of SC and b/t ratio on UCS of different types of backfill. 
Table 6. Fitting relationship between SC, b/t ratio and UCS of backfill samples.

\begin{tabular}{|c|c|c|c|}
\hline Sample Type & CT (d) & Fitting Relationship & $\mathbf{R}^{2}$ \\
\hline \multirow{3}{*}{ СТВ } & 7 & $\mathrm{UCS}=30.54+0.38 \mathrm{x}-1.01 \mathrm{y}+0.005 \mathrm{x}^{2}+0.008 \mathrm{y}^{2}-0.008 \mathrm{xy}$ & 0.9917 \\
\hline & 14 & $\mathrm{UCS}=25.41+1.30 \mathrm{x}-1.03 \mathrm{y}+0.02 \mathrm{x}^{2}+0.01 \mathrm{y}^{2}-0.03 \mathrm{xy}$ & 0.9846 \\
\hline & 28 & $\mathrm{UCS}=91.88+2.24 \mathrm{x}-3.19 \mathrm{y}+0.03 \mathrm{x}^{2}+0.03 \mathrm{y}^{2}-0.04 \mathrm{xy}$ & 0.9933 \\
\hline \multirow{3}{*}{ CFTB1-1 } & 7 & $\mathrm{UCS}=9.91+0.13 \mathrm{x}-0.33 \mathrm{y}+0.002 \mathrm{x}^{2}+0.003 \mathrm{y}^{2}-0.003 \mathrm{xy}$ & 0.9908 \\
\hline & 14 & $\mathrm{UCS}=8.47+1.47 \mathrm{x}-0.54 \mathrm{y}+0.02 \mathrm{x}^{2}+0.01 \mathrm{y}^{2}-0.03 \mathrm{xy}$ & 0.9867 \\
\hline & 28 & $\mathrm{UCS}=110.75+1.75 \mathrm{x}-3.62 \mathrm{y}+0.02 \mathrm{x}^{2}+0.03 \mathrm{y}^{2}-0.03 \mathrm{xy}$ & 0.9884 \\
\hline \multirow{3}{*}{ CFTB1-2 } & 7 & $\mathrm{UCS}=-0.212+0.017 \mathrm{x}-0.005 \mathrm{y}+0.0002 \mathrm{x}^{2}+0.0002 \mathrm{y}^{2}-0.0004 \mathrm{xy}$ & 0.9896 \\
\hline & 14 & $\mathrm{UCS}=12.69+1.29 \mathrm{x}-0.62 \mathrm{y}+0.02 \mathrm{x}^{2}+0.01 \mathrm{y}^{2}-0.03 \mathrm{xy}$ & 0.9934 \\
\hline & 28 & $\mathrm{UCS}=83.81+1.11 \mathrm{x}-2.72 \mathrm{y}+0.02 \mathrm{x}^{2}+0.02 \mathrm{y}^{2}-0.04 \mathrm{xy}$ & 0.9860 \\
\hline \multirow{3}{*}{ CFTB2-1 } & 7 & $\mathrm{UCS}=-2.74+0.15 \mathrm{x}+0.04 \mathrm{y}+0.0007 \mathrm{x}^{2}+0.0001 \mathrm{y}^{2}-0.0025 \mathrm{xy}$ & 0.9810 \\
\hline & 14 & $\mathrm{UCS}=7.32+1.06 \mathrm{x}-0.44 \mathrm{y}+0.014 \mathrm{x}^{2}+0.005 \mathrm{y}^{2}-0.021 \mathrm{xy}$ & 0.9904 \\
\hline & 28 & $\mathrm{UCS}=81.94+1.36 \mathrm{x}-2.69 \mathrm{y}+0.02 \mathrm{x}^{2}+0.02 \mathrm{y}^{2}-0.03 \mathrm{xy}$ & 0.9903 \\
\hline \multirow{3}{*}{ CFTB2-2 } & 7 & $\mathrm{UCS}=0.425+0.034 \mathrm{x}-0.024 \mathrm{y}+0.0002 \mathrm{x}^{2}+0.0003 \mathrm{y}^{2}-0.0007 \mathrm{xy}$ & 0.9730 \\
\hline & 14 & $\mathrm{UCS}=40.24+1.02 \mathrm{x}-1.38 \mathrm{y}+0.01 \mathrm{x}^{2}+0.01 \mathrm{y}^{2}-0.02 \mathrm{xy}$ & 0.9897 \\
\hline & 28 & $\mathrm{UCS}=58.36+1.47 \mathrm{x}-2.00 \mathrm{y}+0.01 \mathrm{x}^{2}+0.02 \mathrm{y}^{2}-0.03 \mathrm{xy}$ & 0.9769 \\
\hline
\end{tabular}

\subsubsection{Comparative Analysis of UCS of Different Types of Backfill Samples}

In order to further understand the influence of FA type and dosage on the UCS of backfill, the difference between the UCS of backfill without FA and the UCS of backfill with FA is obtained. The results are shown in Figure 9.
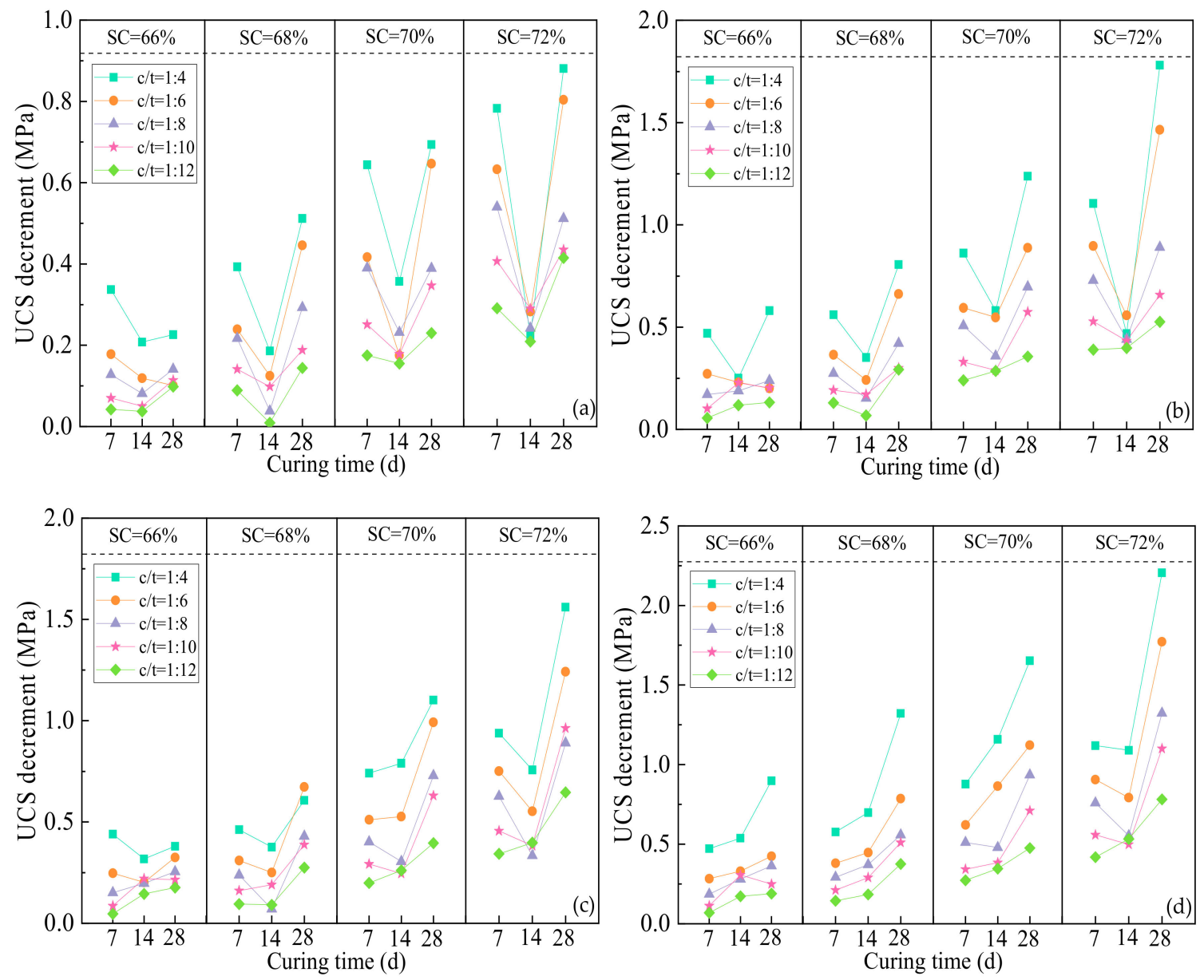

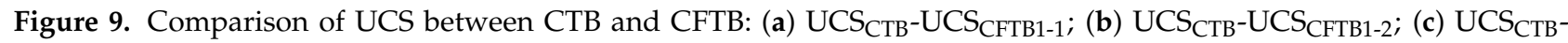
$\mathrm{UCS}_{\mathrm{CFTB2}-1} ;$ (d) $\mathrm{UCS}_{\mathrm{CTB}}-\mathrm{UCS}_{\mathrm{CFTB2-2}}$. 
Figure 9a shows the decrement between the UCS of backfill without FA and the UCS of backfill with an FA1 dosage of $20 \%$. As a whole, keeping the curing age and the $b / t$ ratio constant, the UCS decrement increases as the SC increases. Taking the curing age of $14 \mathrm{~d}$ and the $\mathrm{b} / \mathrm{t}$ ratio of $1: 8$ as an example, when the SC is $66 \%$, the UCS decrement is $0.081 \mathrm{MPa}$; when the SC increased to $68 \%$, the UCS decrement increased to $0.038 \mathrm{MPa}$; when the SC increased to $70 \%$ and $72 \%$, respectively, the UCS decrement increased to 0.232 and $0.242 \mathrm{MPa}$, respectively. Keeping the curing age and the SC constant, the UCS decrement decreases as the $\mathrm{b} / \mathrm{t}$ ratio decreases. Taking the curing age of $14 \mathrm{~d}$ and the SC of $68 \%$ as an example, when the $\mathrm{b} / \mathrm{t}$ ratio is $1: 4$, the UCS decrement is $0.186 \mathrm{MPa}$; when the $\mathrm{b} / \mathrm{t}$ ratio reduced to $1: 6,1: 8,1: 10$, and 1:12, respectively, the UCS decrement reduced to $0.125,0.038,0.098$, and $0.009 \mathrm{MPa}$, respectively. Keeping the SC and the $\mathrm{b} / \mathrm{t}$ ratio constant, as the curing age increases, the UCS decrement first decreases and then increases, and the general distribution pattern is the shape of a ' $\mathrm{V}$ '. Taking the SC of $68 \%$ and the $\mathrm{b} / \mathrm{t}$ ratio of $1: 8$ as an example, when the curing age is $7 \mathrm{~d}$, the UCS decrement is $0.217 \mathrm{MPa}$; when the curing age increased to $14 \mathrm{~d}$, the UCS decrement reduced to $0.038 \mathrm{MPa}$; when the curing age increased to $28 \mathrm{~d}$, the UCS decrement increased to $0.293 \mathrm{MPa}$.

Figure $9 \mathrm{~b}$ shows the UCS decrement between the UCS of backfill without FA and the UCS of backfill with the FA1 dosage of $50 \%$. As a whole, keep the curing age and the $b / t$ ratio constant, the UCS decrement increases as the SC increases. Taking the curing age of $28 \mathrm{~d}$ and the $\mathrm{b} / \mathrm{t}$ ratio of 1:4 as an example, when the SC is $66 \%$, the UCS decrement is $0.581 \mathrm{MPa}$; when the SC increased to $68 \%, 70 \%$, and $72 \%$, respectively, the UCS decrement increased to $0.806,1.238$, and $1.781 \mathrm{MPa}$, respectively. Keeping the curing age and the SC constant, the UCS decrement decreases as the $b / t$ ratio decreases. Taking the curing age of $28 \mathrm{~d}$ and the SC of $70 \%$ as an example, when the $b / t$ ratio is $1: 4$, the UCS decrement is $1.781 \mathrm{MPa}$; when the $\mathrm{b} / \mathrm{t}$ ratio reduced to $1: 6,1: 8,1: 10$, and $1: 12$, respectively, the UCS decrement reduced to $1.465,0.890,0.658$, and $0.526 \mathrm{MPa}$, respectively. Keep the SC and the $b / t$ ratio constant, as the curing age increases, the UCS decrement first decreases and then increases, the distribution pattern is the shape of a ' $\mathrm{V}$ '. Taking the SC of $68 \%$ and the $\mathrm{b} / \mathrm{t}$ ratio of $1: 4$ as an example, when the curing age is $7 \mathrm{~d}$, the UCS decrement is $0.561 \mathrm{MPa}$; when the curing age increased to $14 \mathrm{~d}$, the UCS decrement reduced to $0.352 \mathrm{MPa}$; when the curing age increased to $28 \mathrm{~d}$, the UCS decrement increased to $0.806 \mathrm{MPa}$.

Figure 9c shows the UCS decrement between the UCS of backfill without FA and the UCS of backfill with FA2 dosage of $20 \%$. As a whole, keep the curing age and the $\mathrm{b} / \mathrm{t}$ ratio constant, the UCS decrement increases as the SC increases. Taking the curing age of $28 \mathrm{~d}$ and the $\mathrm{b} / \mathrm{t}$ ratio of $1: 4$ as an example, when the SC is $66 \%$, the UCS decrement is $0.380 \mathrm{MPa}$; when the SC increased to $68 \%, 70 \%$, and $72 \%$, respectively, the UCS decrement increased to $0.607,1.102$, and $1.561 \mathrm{MPa}$, respectively. Keep the curing age and the SC constant, the UCS decrement decreases as the $\mathrm{b} / \mathrm{t}$ ratio decreases. Taking the curing age of $7 \mathrm{~d}$ and the $\mathrm{SC}$ of $70 \%$ as an example, when the $b / t$ ratio is $1: 4,1: 6,1: 8,1: 10$, and $1: 12$, respectively, the corresponding UCS decrement is $0.938,0.715,0.627,0.456$, and $0.343 \mathrm{MPa}$, respectively. Keeping the SC and the b/t ratio constant, as the curing age increases, the UCS decrement first decreases and then increases, the distribution pattern is the shape of a ' $\mathrm{V}$ '. Taking the SC of $72 \%$ and the $b / t$ ratio of $1: 4$ as an example, when the curing age is 7,14 , and 28 , respectively, corresponding UCS decrement is $0.938,0.757$, and 1.561 , respectively.

Figure $9 \mathrm{~d}$ shows the UCS decrement between the UCS of backfill without FA and the UCS of backfill with FA2 dosage of $50 \%$. Keep the curing age and the b/t ratio constant, the UCS decrement increases as the SC increases. Keeping the curing age and the SC constant, the UCS decrement decreases as the $b / t$ ratio decreases. Keeping the curing age and the $\mathrm{b} / \mathrm{t}$ ratio constant, when the SC is $66 \%, 68 \%$, and $70 \%$, the UCS decrement increases as the curing age increases; when the SC is $72 \%$, as the curing age increases, the UCS decrement first decreases and then increases.

A comprehensive analysis of Figure $9 a-d$ shows that compared to the UCS of CTB, the UCS decrement of backfill with FA increases as the SC increases, decreases as the b/t ratio decreases, first increases and then decreases as the curing age increases. An analysis of the 
reasons shows that as the SC increases, the porosity inside the backfill decreases, the UCS of CTB and the UCS of backfill with FA both increase, then due to the addition of FA, the UCS increment of the backfill with FA decreases, and causes the UCS decrement to increase. As the $b / t$ ratio decreases, the content of binder inside the backfill decreases, the C-S-H gel produced by the hydration reaction decreases, the UCS of CTB and the UCS of backfill with FA both decreases, the smaller the $b / t$ ratio, the smaller the difference of the C-S-H gel produced by hydration reaction inside the backfill, so the UCS decrement decreases. In the initial curing phase $(C T=7 d)$, the binder inside the backfill rapidly hydrates with water and tailings particles, which results in the strength increasing rapidly, the strength of the backfill varies greatly with different types; in the curing interim $(\mathrm{CT}=14 \mathrm{~d})$, the hydration reaction process inside the backfill is almost complete, the strength of backfill reaches a high level with different types, and the strength difference decreases; in the curing later period (28d), the hydration reaction inside the backfill is basically over, the strength of the backfill no longer changes significantly with the curing age, and the strength of different types of backfill is close to its peak strength, leading to a strength difference increase again.

Figure 10 shows the strength difference results between the backfill sample with FA of different SC, different $b / t$ ratio, and different curing ages. Figure $10 a$ shows the strength difference results between the backfill with an FA1 dosage of $20 \%$ and the backfill with an FA1 dosage of 50\%. It can be seen from Figure 10a that all of the results are positive, and it shows that the UCS of backfill decreases as the FA1 dosage increases. Keeping the curing age and the $\mathrm{b} / \mathrm{t}$ ratio constant, the UCS decrement increases as the SC increases, taking the $\mathrm{b} / \mathrm{t}$ ratio of $1: 4$ as an example, when the SC increased from $66 \%$ to $72 \%$ at the curing age of $7 \mathrm{~d}$, the UCS decrement increased from 0.133 to $0.322 \mathrm{MPa}$; when the SC increased from $66 \%$ to $72 \%$ at the curing age of $14 \mathrm{~d}$, the UCS decrement increased from 0.043 to $0.245 \mathrm{MPa}$; when the curing age was $28 \mathrm{~d}$, the corresponding UCS decrement increased from 0.355 to $0.900 \mathrm{MPa}$. Keeping the curing age and the SC constant, the UCS decrement decreases as the $\mathrm{b} / \mathrm{t}$ ratio decreases, taking the $\mathrm{SC}$ of $68 \%$ as an example, when the $\mathrm{b} / \mathrm{t}$ ratio decreased from 1:4 to 1:12 at the curing age of $7 d$, the UCS decrement decreased from 0.168 to $0.041 \mathrm{MPa}$; when the curing age was 14 and $28 \mathrm{~d}$, respectively, the corresponding UCS decrement decreased from 0.166 to $0.059 \mathrm{MPa}$ and decreased from 0.294 to $0.149 \mathrm{MPa}$, respectively. Keeping the SC and the $b / t$ ratio constant, as the curing age increases, the UCS decrement increases slowly first and then quickly. Taking the SC of $68 \%$ and the $b / t$ ratio of $1: 12$ as an example, when the curing age is $7 \mathrm{~d}$, the UCS decrement is $0.041 \mathrm{MPa}$; when the curing age is $14 \mathrm{~d}$, the UCS decrement is increased to $0.059 \mathrm{MPa}$; when the curing age is $28 \mathrm{~d}$, the UCS decrement is increased to $0.149 \mathrm{MPa}$. Figure $10 \mathrm{~b}$ shows the strength difference results between the backfill with an FA2 dosage of $20 \%$ and the backfill with an FA2 dosage of $50 \%$. It can be seen from Figure $10 \mathrm{~b}$ that all of the results are positive, and it shows the UCS of backfill decreases as the dosage of FA2 increases. When the SC is $66 \%, 68 \%$, and $70 \%$, as the curing age increases, the UCS decrement shows a trend of increase first and then a decrease; when the SC is $72 \%$, as the curing age increases, the UCS decrement increases slowly first and then quickly. Under the same curing age and SC condition, the UCS decrement decreases as the $b / t$ ratio decreases. Under the same curing age and $b / t$ ratio condition, the UCS decrement increases as the SC increases. Figure 10c, d shows the strength difference results between the backfill with FA1 and the backfill with FA2 when the dosage of FA is $20 \%$ and $50 \%$, respectively. All of the results in the figure are positive, and it shows under the same FA dosage condition that the strength of backfill with FA1 is bigger than backfill with FA2. The results shown in Figure 10c,d show no obvious pattern, but on the whole, under the same curing age and $b / t$ ratio condition, the UCS decrement increases as the SC increases; under the same curing age and SC condition, the UCS decrement decreases as the $b / t$ ratio decreases; under the same $S C$ and $b / t$ ratio condition, as the curing age increases, the UCS decrement first increases and then decreases. 

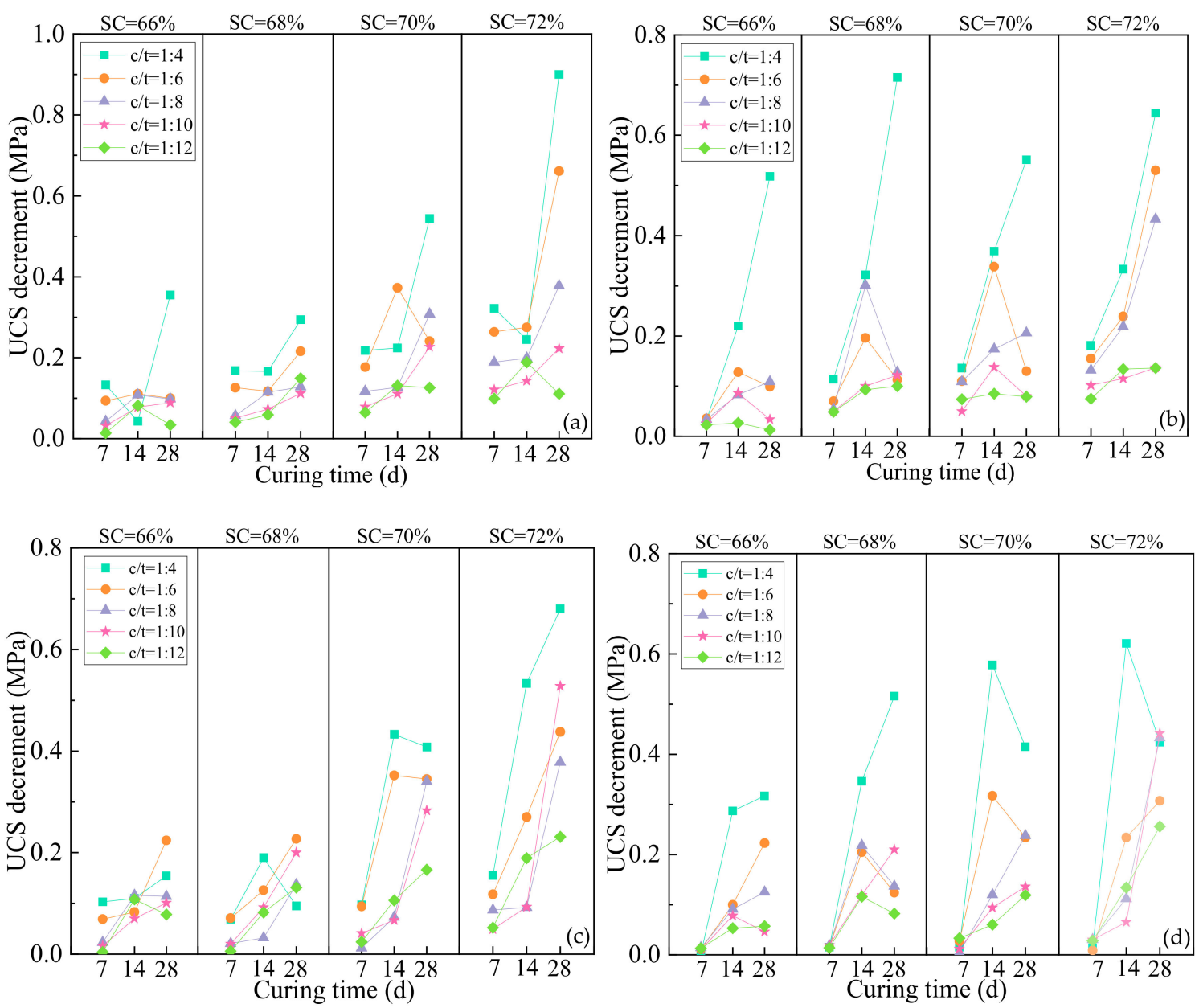

Figure 10. Comparison of UCS of different types of CFTB:

(a) $\mathrm{UCS}_{\mathrm{CFTB1-1}}-\mathrm{UCS}_{\mathrm{CFTB1-2}}$; (b) UCS $\mathrm{UCFT2-1}_{\mathrm{C}} \mathrm{UCS}_{\mathrm{CFTB2}-2}$; (c) $\mathrm{UCS}_{\mathrm{CFTB2-1}}-\mathrm{UCS}_{\mathrm{CFTB1-1}}$; (d) UCS $\mathrm{UFTB2-2}_{\text {-UCS }} \mathrm{CFTB2-1}_{\text {. }}$

\subsection{Relation Between UCS of Backfill and Its Viscosity}

According to the previous research, we can see that the viscosity and the UCS of backfill show the same pattern of change, they both increases as the SC, the b/t ratio, and the curing age increase. The change mechanism of backfill viscosity and UCS is also very similar, as the SC increases, the solid particle content increases, internal pores decrease, the friction action between particle and particle increases, strength and viscosity increases; as the $b / t$ ratio increases, the binder particle content inside the backfill increases, the amount of gels produced by hydration reaction also increases, strength and viscosity increases; as the curing age increases, the hydration reaction inside the backfill is sufficient, the amount of gels produced by the hydration reaction also increases, and strength and viscosity increases. Therefore, whether there is a certain internal relationship between the backfill viscosity and its strength, the viscosity results can be used to reasonably represent the strength results. Figure 11 shows the relationship diagram between the viscosity and the strength of the backfill of different types under the three curing age conditions. Figure 11a shows the relationship between the viscosity and strength of the CTB sample under the three curing ages, use linear fitting for the relationship between them, the fitting multiple correlation coefficient $R^{2}$ is $0.9662,0.9316$, and 0.9720 , respectively, and the fitting multiple correlation coefficients $R^{2}$ are all greater than 0.9 , so the CTB viscosity had a good linear functional relationship with its strength. Figure $11 \mathrm{~b}-\mathrm{e}$ is the relationship diagram between the viscosity and strength of CFTB1-1, CFTB1-2, CFTB2-1, and CFTB2-2, respectively. A linear function is also used for fitting analysis, under the three curing age conditions, the fitting degree of the viscosity and UCS of CFTB1-1 is $0.9593,0.9071$, 
and 0.9298 , respectively; the fitting degree of the viscosity and UCS of CFTB1-2 is 0.9675 , 0.9300 , and 0.9486 , respectively; the fitting degree of the viscosity and UCS of CFTB2-1 is $0.9710,0.9198$, and 0.9252 , respectively; the fitting degree of the viscosity and UCS of CFTB22 is $0.9503,0.9345$, and 0.9418 , respectively. The fitted multiple correlation coefficients $R^{2}$ are all greater than 0.9 ; therefore, a comprehensive analysis shows that the linear function can better characterize the internal relationship between the viscosity and UCS of backfill.
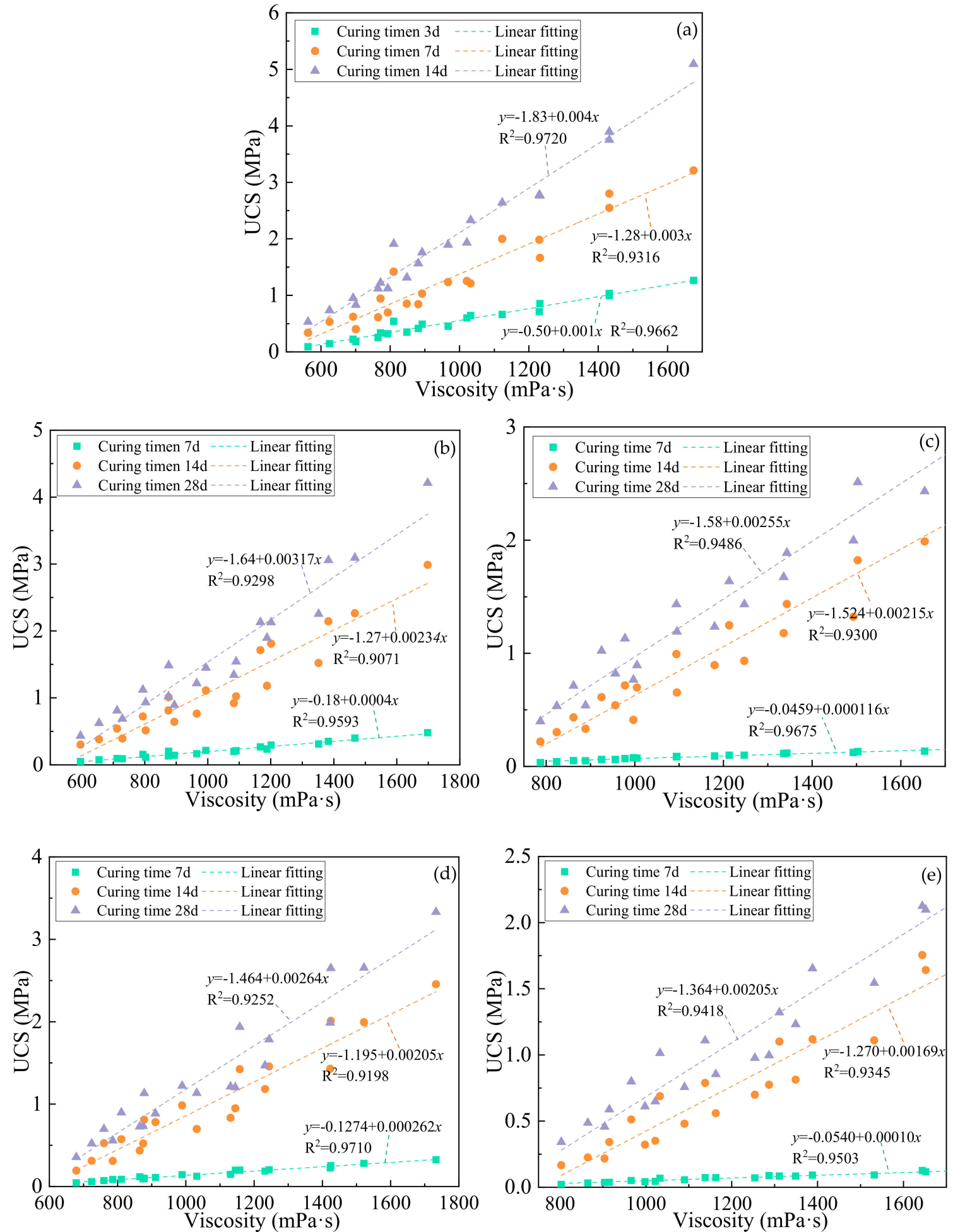

Figure 11. Relation between UCS and viscosity: (a) CTB; (b) CFTB1-1; (c) CFTB1-2; (d) CFTB2-1; (e) CFTB2-1. 


\subsection{Prediction of Backfill Strength}

The results of the previous chapters show that there is a linear functional relationship between the viscosity and UCS of different types of backfill. The viscosity parameter measurement of backfill is more simple, convenient, and efficient, so the viscosity parameter of backfill can be used to predict its strength parameter. According to the functional relationship between the viscosity and strength of different curing ages of the backfill sample in Figure 11, the difference between the test value and the predicted value can be obtained under different curing ages, and the results are shown in Figure 12. It can be seen from Figure 12 that the majority of the different ranges between the test value and the predicted value is controlled within $20 \%$, only a few data points are scattered beyond the $20 \%$ range, so it is considered that the strength test value of the backfill sample differs little with the predicted value, and the predicted result is relatively reliable.
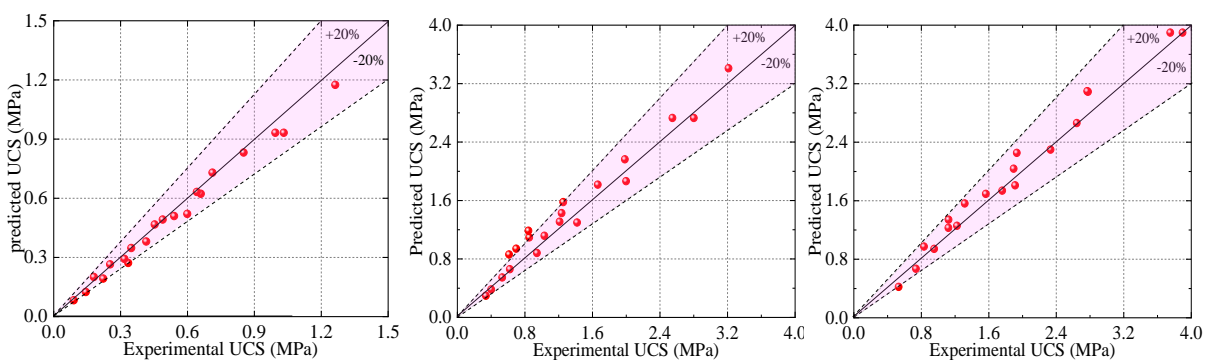

(a) CTB
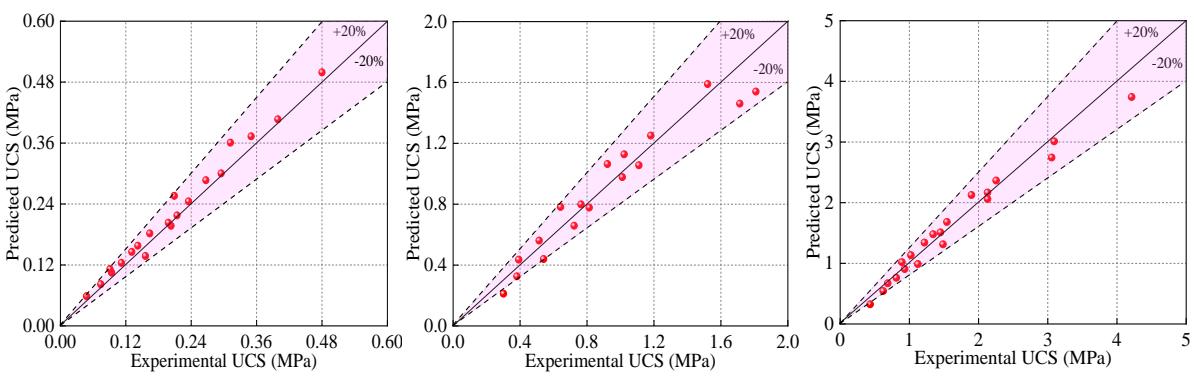

(b) CFTB1-1
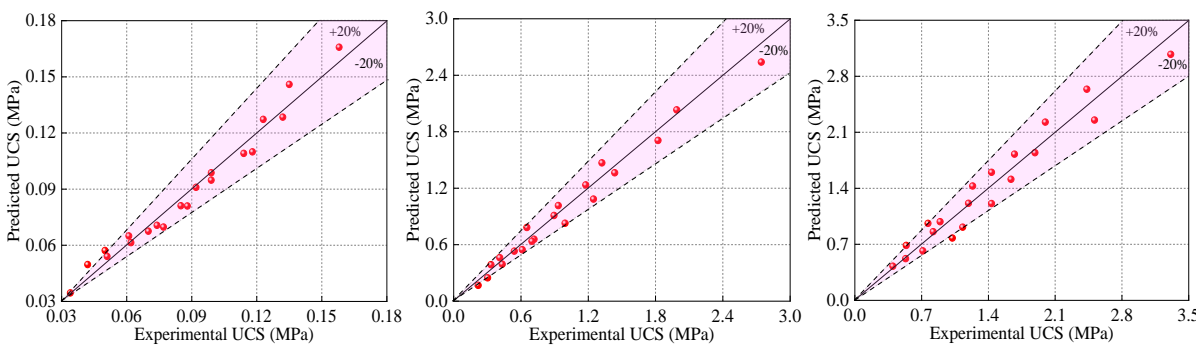

(c) CFTB1-2
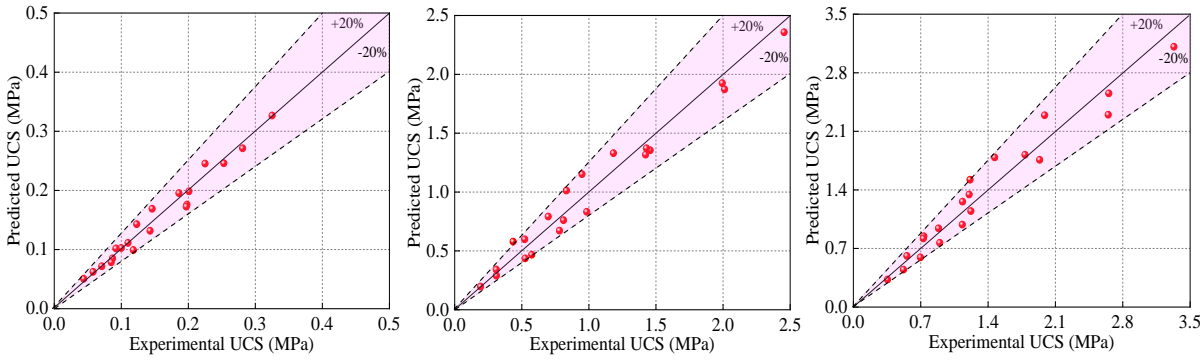

(d) CFTB2-1

Figure 12. Cont. 

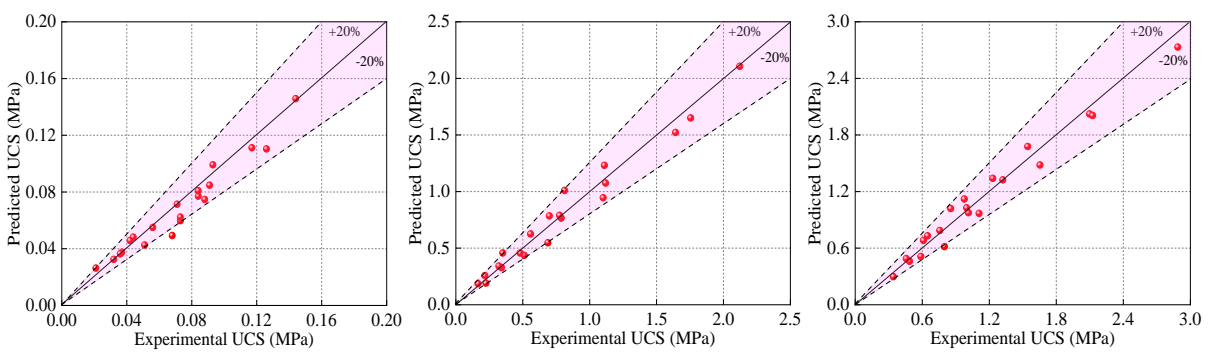

(e) CFTB2-2

Figure 12. Deviations between experimental UCS and predicted UCS of different type backfill samples.

In addition to fitting analysis, statistical differences between the test values and the predicted values should also be evaluated to determine that the functional relationship between the viscosity and strength of backfill can be used reliably for backfill strength prediction. Given UCS test data of any backfill sample is ofi, the corresponding prediction UCS for its viscosity is opi, and the total sample is Na. Introducing Mean Square Error (MSE), Root Mean Square Error (RMSE), Mean Absolute Error (MAE), and Mean Absolute Percentage Error (MAPE), we evaluated the error of the UCS test value and prediction value. The evaluation indexes of various evaluation models are shown in Table 7.

$$
\begin{gathered}
M S E=\frac{\sum_{i=1}^{N_{a}}\left(\sigma_{p i}-\sigma_{f i}\right)^{2}}{N_{a}} \\
R M S E=\sqrt{\frac{\sum_{i=1}^{N_{a}}\left(\sigma_{p i}-\sigma_{f i}\right)^{2}}{N_{a}}} \\
M A E=\frac{\sum_{i=1}^{N_{a}}\left|\sigma_{p i}-\sigma_{f i}\right|}{N_{a}} \\
M A P E=\frac{1}{N_{a}} \sum_{i=1}^{N_{a}}\left|\frac{\sigma_{p i}-\sigma_{f i}}{\sigma_{p i}}\right| \times 100 \%
\end{gathered}
$$

Table 7. Evaluation Indexes of UCS prediction models for different types of backfill samples.

\begin{tabular}{cccccc}
\hline Scheme. & CT $(\mathbf{d})$ & MSE & RMSE & MAE & MAPE/\% \\
\hline \multirow{2}{*}{ CTB } & 7 & 0.002 & 0.044 & 0.033 & 7.8 \\
& 14 & 0.032 & 0.178 & 0.150 & 11.9 \\
CFTB1-1 & 28 & 0.030 & 0.172 & 0.136 & 8.1 \\
& 7 & 0.001 & 0.020 & 0.016 & 8.7 \\
& 14 & 0.017 & 0.131 & 0.107 & 11.7 \\
CFTB1-2 & 28 & 0.028 & 0.166 & 0.130 & 9.3 \\
& 7 & 0.001 & 0.005 & 0.005 & 5.5 \\
& 14 & 0.009 & 0.097 & 0.082 & 10.9 \\
CFTB2-1 & 28 & 0.028 & 0.168 & 0.146 & 11.7 \\
& 7 & 0.001 & 0.013 & 0.010 & 7.4 \\
\hline \multirow{2}{*}{ CFTB2-2 } & 28 & 0.012 & 0.111 & 0.099 & 11.7 \\
& 7 & 0.031 & 0.177 & 0.148 & 11.5 \\
\hline
\end{tabular}


It can be seen from Table 7 that MSE indexes are all less than 0.1, RMSE indexes are all less than 0.2, MAE indexes are all less than 0.2, MAPE indexes are all less than $15 \%$, and most MAPE indexes are all less than $10 \%$. Based on the above results, it can be concluded that the adoption of the backfill viscosity parameter to predict its strength parameter is reasonable and reliable.

In order to show the difference between the UCS predicted value and the UCS test value more intuitively, Figure 13 shows the comparison between the UCS predicted value and the test value under 60 test conditions for five types of backfill. It can be seen from Figure 13 that the predicted value of UCS of backfill is consistent with the distribution pattern of the test value, and the two results are very consistent. Therefore, it can be judged that the above prediction model is reliable.
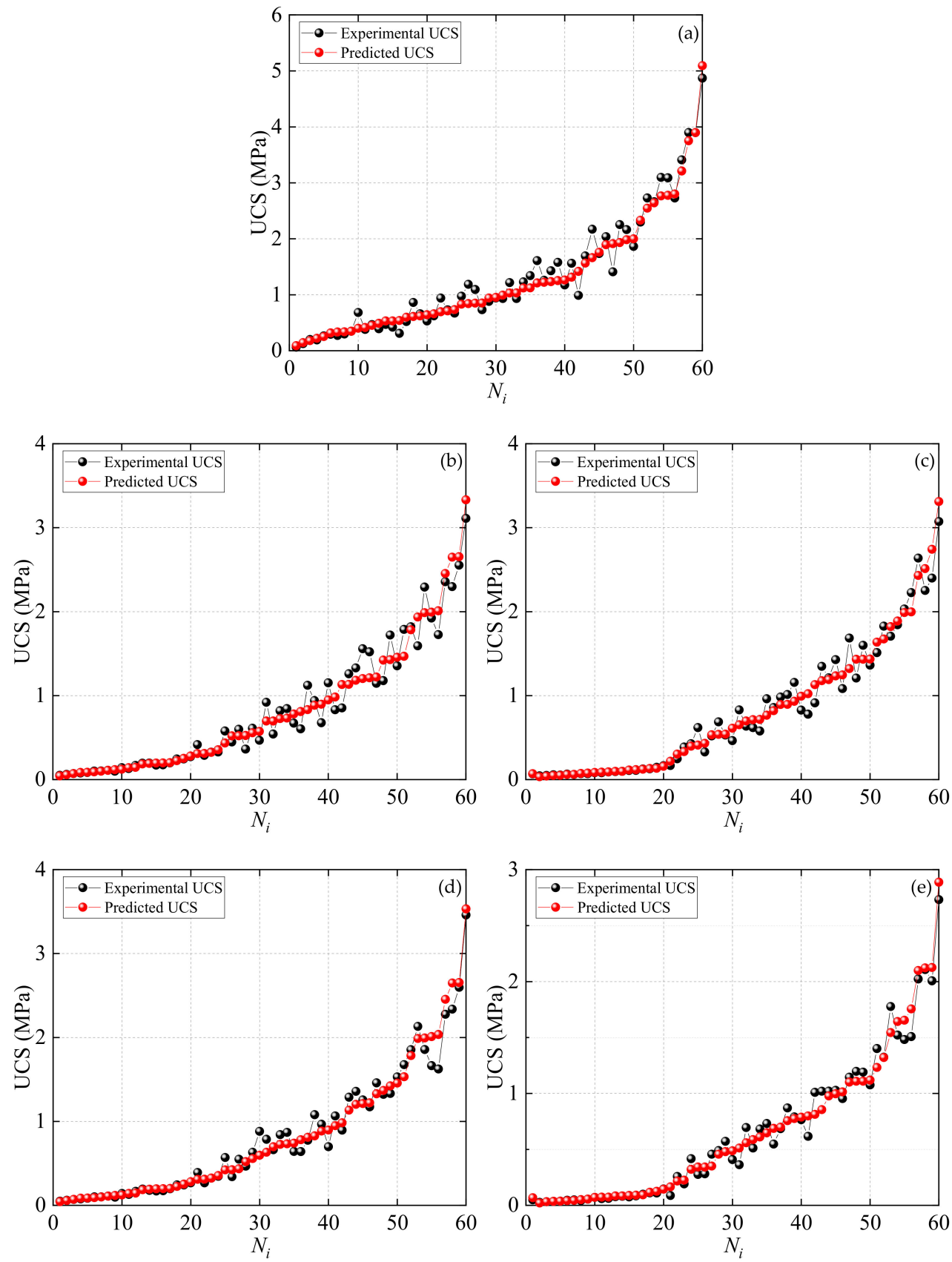

Figure 13. Comparison between experimental UCS and predicted UCS of different type backfill Scheme 1. (a) CTB; (b) CFTB1-1; (c) CFTB1-2; (d) CFTB2-1; (e) CFTB2-2. 


\section{Conclusions}

In this study, two types of fly ash as a fractional OPC replacement were investigated for tailings backfill. Following are the main conclusions drawn from this study:

(1) As SC increases, the viscosity of the backfill slurry increases as a power function. As the $b / t$ ratio decreases, the viscosity of the backfill slurry decreases as an exponential function. The coupling effect of $S C$ and $b / t$ ratio has a great influence on the viscosity of the backfill slurry. The relationship between $\mathrm{SC}, \mathrm{b} / \mathrm{t}$ ratio and viscosity are a quadratic polynomial function of $z=a+b x+c y+d x^{2}+e y^{2}+f x y$.

(2) The viscosity of the backfill slurry mixed with binder is higher than that of a pure tailings slurry. The viscosity of the backfill slurry mixed with FA is higher than that of the backfill slurry without FA. The viscosity of the backfill slurry mixed with FA2 is higher than that of the backfill slurry mixed with FA1. The more FA is added, the higher the viscosity.

(3) With the increase of SC, the UCS of backfill increases as a power function. With the decrease of the $b / t$ ratio, the UCS of all backfill samples decreases as an exponential function. The UCS of all backfill samples increased with an increase of curing time. The coupling effect of the SC and $b / t$ ratio has a great influence on the UCS of backfill samples. The relationship between $\mathrm{SC}, \mathrm{b} / \mathrm{t}$ ratio and viscosity are a quadratic polynomial function of $z=a+b x+c y+d x^{2}+e y^{2}+f x y$.

(4) The UCS of the backfill samples mixed with FA is smaller than that without FA. The higher the FA dosage is, the smaller the UCS of the backfill sample is. At the same FA dosage, the UCS of the backfill sample mixed with FA2 is smaller than that of mixed with FA1.

(5) The UCS of backfill increases with the increase of viscosity, and both of them show a good linear function relationship. The fitting multiple correlation coefficient $R^{2}$ is higher than 0.9. According to the functional relationship between viscosity and UCS, the viscosity is used to predict the strength of the backfill. The error range of the prediction result is within $15 \%$, and the majority of the error range is within $10 \%$, indicating that it is feasible to use the viscosity parameter to predict the strength parameter of the backfill.

Author Contributions: J.W. and J.F. analyzed the experimental data and initiated the writing of the paper; W.S. modified the manuscript; Y.Z. corrected the English writing. All authors have read and agreed to the published version of the manuscript.

Funding: This research was supported the National Natural Science Foundation of China (Grant No. 51974012), the National Natural Science Foundation of China Youth Fund (51804016), and the Fundamental Research Funds for the Central Universities (FRF-BD-19-005A).

Acknowledgments: The experimental works described in this study were conducted at the Key Laboratory of High-Efficient Mining and Safety of Metal Mines of the Ministry of Education in the University of Science and Technology, Beijing. The authors gratefully acknowledge the staff and students at the laboratory for technical help during testing.

Conflicts of Interest: The authors declare no conflict of interest.

\section{References}

1. Sofrá, F.; Boger, D. Environmental rheology for waste minimisation in the minerals industry. Chem. Eng. J. 2002, 86, 319-330. [CrossRef]

2. Belem, T.; Benzaazoua, M. Design and Application of Underground Mine Paste Backfill Technology. Geotech. Geol. Eng. 2008, 26, 147-174. [CrossRef]

3. Fu, J.X.; Song, W.D.; Tan, Y.Y. Study of stability and evolution indexes of gobs under unloading effect in the deep mines. Geomech. Geoeng. 2018, 14, 439-451.

4. Fu, J.X.; Song, W.D.; Tan, Y.Y. Study on microstructural evolution and strength growth and fracture mechanism of cemented tailings backfill. Adv. Mater. Sci. Eng. 2016, 2016, 1-13. [CrossRef]

5. Fourie, A. Preventing catastrophic failures and mitigating environmental impacts of tailings storage facilities. Procedia Earth Planet. Sci. 2009, 1, 1067-1071. [CrossRef] 
6. He, X.; Zheng, C.; Sui, X.; Jing, Q.; Wu, X.; Wang, J.; Si, W.; Zhang, X.-F. Biological damage to Sprague-Dawley rats by excessive anions contaminated groundwater from rare earth metals tailings pond seepage. J. Clean. Prod. 2018, 185, 523-532. [CrossRef]

7. Fu, J.; Song, W.; Tan, Y. Criterion of local energy release rate of gob instability in deep mines considering unloading stress path. Int. J. Min. Sci. Technol. 2017, 27, 1011-1017. [CrossRef]

8. Xie, S.-R.; Pan, H.; Chen, D.; Zeng, J.-C.; Song, H.-Z.; Cheng, Q.; Xiao, H.-B.; Yan, Z.-Q.; Li, Y.-H. Stability analysis of integral load-bearing structure of surrounding rock of gob-side entry retention with flexible concrete formwork. Tunn. Undergr. Space Technol. 2020, 103, 103492. [CrossRef]

9. Tariq, A.; Yanful, E.K. A review of binders used in cemented paste tailings for underground and surface disposal practices. $J$. Environ. Manag. 2013, 131, 138-149. [CrossRef]

10. Qi, C.; Fourie, A.; Chen, Q. Neural network and particle swarm optimization for predicting the unconfined compressive strength of cemented paste backfill. Constr. Build. Mater. 2018, 159, 473-478. [CrossRef]

11. Yilmaz, E. Advances in reducing large volumes of environmentally harmful mine waste rocks and tailings. Miner. Resour. Manag. 2011, 27, 89-112.

12. Zhang, N.; Yuan, L.; Han, C.; Xue, J.; Kan, J. Stability and deformation of surrounding rock in pillarless gob-side entry retaining. Saf. Sci. 2012, 50, 593-599. [CrossRef]

13. Ouellet, S.; Bussière, B.; Mbonimpa, M.; Benzaazoua, M.; Aubertin, M. Reactivity and mineralogical evolution of an underground mine sulphidic cemented paste backfill. Miner. Eng. 2006, 19, 407-419. [CrossRef]

14. Benzaazoua, M.; Bussière, B.; Demers, I.; Aubertin, M.; Fried, É.; Blier, A. Integrated mine tailings management by combining environmental desulphurization and cemented paste backfill: Application to mine Doyon, Quebec, Canada. Miner. Eng. 2008, 21, 330-340. [CrossRef]

15. Edraki, M.; Baumgartl, T.; Manlapig, E.; Bradshaw, D.; Franks, D.M.; Moran, C.J. Designing mine tailings for better environmental, social and economic outcomes: A review of alternative approaches. J. Clean. Prod. 2014, 84, 411-420. [CrossRef]

16. Sivakugan, N.; Veenstra, R.; Naguleswaran, N. Underground Mine Backfilling in Australia Using Paste Fills and Hydraulic Fills. Int. J. Geosynth. Ground Eng. 2015, 1, 1-7. [CrossRef]

17. Benzaazoua, M.; Fall, M.; Belem, T. A contribution to understanding the hardening process of cemented paste backfill. Miner. Eng. 2004, 17, 141-152. [CrossRef]

18. Xue, Z.; Gan, D.; Zhang, Y.; Liu, Z. Rheological behavior of ultrafine-tailings cemented paste backfill in high-temperature mining conditions. Constr. Build. Mater. 2020, 253, 119212. [CrossRef]

19. He, Y.; Chen, Q.; Qi, C.; Zhang, Q.; Xiao, C. Lithium slag and fly ash-based binder for cemented fine tailings backfill. J. Environ. Manag. 2019, 248, 109282. [CrossRef]

20. Huang, L.; Yan, P.; Liu, Y. Effect of alkali content in cement on the fluidity and structural build-up of plasticized cement pastes. Constr. Build. Mater. 2020, 253, 119180. [CrossRef]

21. Rößler, C.; Eberhardt, B.A.; Kučerova, H.; Moser, B. Influence of hydration on the fluidity of normal Portland cement pastes. Cem. Concr. Res. 2008, 38, 897-906. [CrossRef]

22. Uchikawa, H.; Hanehara, S.; Shirasaka, T.; Sawaki, D. Effect of admixture on hydration of cement, adsorptive behavior of admixture and fluidity and setting of fresh cement paste. Cem. Concr. Res. 1992, 22, 1115-1129. [CrossRef]

23. Liu, L.; Xin, J.; Qi, C.; Jia, H.; Song, K.-I. Experimental investigation of mechanical, hydration, microstructure and electrical properties of cemented paste backfill. Constr. Build. Mater. 2020, 263, 120137. [CrossRef]

24. Panchal, S.; Deb, D.; Sreenivas, T. Variability in rheology of cemented paste backfill with hydration age, binder and superplasticizer dosages. Adv. Powder Technol. 2018, 29, 2211-2220. [CrossRef]

25. Fang, K.; Fall, M. Effects of curing temperature on shear behavior of cemented paste backfill-rock interface. Int. J. Rock Mech. Min. Sci. 2018, 112, 184-192. [CrossRef]

26. Cao, S.; Yilmaz, E.; Song, W. Evaluation of Viscosity, Strength and Microstructural Properties of Cemented Tailings Backfill. Minerals 2018, 8, 352. [CrossRef]

27. Qi, C.; Fourie, A. Cemented paste backfill for mineral tailings management: Review and future perspectives. Miner. Eng. 2019, 144, 106025. [CrossRef]

28. Liu, L.; Fang, Z.; Qi, C.; Zhang, B.; Guo, L.; Song, K.-I. Numerical study on the pipe flow characteristics of the cemented paste backfill slurry considering hydration effects. Powder Technol. 2019, 343, 454-464. [CrossRef]

29. Zhou, X.; Hu, S.; Zhang, G.; Li, J.; Xuan, D.; Gao, W. Experimental investigation and mathematical strength model study on the mechanical properties of cemented paste backfill. Constr. Build. Mater. 2019, 226, 524-533. [CrossRef]

30. Ercikdi, B.; Yllmaz, T.; Külekci, G. Strength and ultrasonic properties of cemented paste backfill. Ultrasonics 2014, 54, 195-204. [CrossRef]

31. Zhao, K.; Yu, X.; Zhu, S.; Yan, Y.; Zhou, Y.; He, Z.; Song, Y.; Huang, M. Acoustic emission fractal characteristics and mechanical damage mechanism of cemented paste backfill prepared with tantalum niobium mine tailings. Constr. Build. Mater. 2020, 258, 119720. [CrossRef]

32. Lu, H.; Qi, C.; Chen, Q.; Gan, D.; Xue, Z.; Hu, Y. A new procedure for recycling waste tailings as cemented paste backfill to underground stopes and open pits. J. Clean. Prod. 2018, 188, 601-612. [CrossRef]

33. Dong, Q.; Liang, B.; Jia, L.; Jiang, L. Effect of sulfide on the long-term strength of lead-zinc tailings cemented paste backfill. Constr. Build. Mater. 2019, 200, 436-446. [CrossRef] 
34. Zheng, J.R.; Sun, X.X.; Guo, L.J.; Zhang, S.M.; Chen, J.Y. Strength and hydration products of cemented paste backfill from sulphide-rich tailings using reactive MgO-activated slag as a binder. Constr. Build. Mater. 2019, 203, 111-119. [CrossRef]

35. Bull, A.J.; Fall, M. Curing temperature dependency of the release of arsenic from cemented paste backfill made with Portland cement. J. Environ. Manag. 2020, 269, 110772. [CrossRef]

36. Libos, I.L.S.; Cui, L. Effects of curing time, cement content, and saturation state on mode-I fracture toughness of cemented paste backfill. Eng. Fract. Mech. 2020, 235, 107174. [CrossRef]

37. Cui, L.; Fall, M. Mechanical and thermal properties of cemented tailings materials at early ages: Influence of initial temperature, curing stress and drainage conditions. Constr. Build. Mater. 2016, 125, 553-563. [CrossRef]

38. Yilmaz, E.; Benzaazoua, M.; Belem, T.; Bussière, B. Effect of curing under pressure on compressive strength development of cemented paste backfill. Miner. Eng. 2009, 22, 772-785. [CrossRef]

39. Yingliang, Z.; Jingping, Q.; Xing, J.; Sun, X. Recycling of quarry dust for supplementary cementitious materials in low carbon cement. Constr. Build. Mater. 2020, 237, 117608. [CrossRef]

40. Saedi, A.; Jamshidi-Zanjani, A.; Darban, A.K. A review on different methods of activating tailings to improve their cementitious property as cemented paste and reusability. J. Environ. Manag. 2020, 270, 110881. [CrossRef]

41. Peyronnard, O.; Benzaazoua, M. Estimation of the cementitious properties of various industrial by-products for applications requiring low mechanical strength. Resour. Conserv. Recycl. 2011, 56, 22-33. [CrossRef]

42. Yan, B.; Ren, F.; Cai, M.; Qiao, C. Influence of new hydrophobic agent on the mechanical properties of modified cemented paste backfill. J. Mater. Res. Technol. 2019, 8, 5716-5727. [CrossRef]

43. Chen, X.; Shi, X.; Zhou, J.; Chen, Q.; Li, E.; Du, X. Compressive behavior and microstructural properties of tailings polypropylene fibre-reinforced cemented paste backfill. Constr. Build. Mater. 2018, 190, 211-221. [CrossRef]

44. Yi, X.; Ma, G.; Fourie, A. Centrifuge model studies on the stability of fibre-reinforced cemented paste backfill stopes. Geotext. Geomembr. 2018, 46, 396-401. [CrossRef]

45. Liu, Y.; Li, H.; Wang, K.; Wu, H.; Cui, B. Effects of accelerator-water reducer admixture on performance of cemented paste backfill. Constr. Build. Mater. 2020, 242, 118187. [CrossRef]

46. Marquez, M.; Robben, A.; Grady, B.P.; Robb, I. Viscosity and yield stress reduction in non-colloidal concentrated suspensions by surface modification with polymers and surfactants and/or nanoparticle addition. J. Colloid Interface Sci. 2006, 295, 374-387. [CrossRef]

47. Li, W.; Fall, M. Sulphate effect on the early age strength and self-desiccation of cemented paste backfill. Constr. Build. Mater. 2016, 106, 296-304. [CrossRef]

48. Yin, S.; Shao, Y.; Wu, A.; Wang, Z.; Yang, L. Assessment of expansion and strength properties of sulfidic cemented paste backfill cored from deep underground stopes. Constr. Build. Mater. 2020, 230, 116983. [CrossRef]

49. Kesimal, A.; Yilmaz, E.; Ercikdi, B.; Alp, I.; Deveci, H. Effect of properties of tailings and binder on the short-and long-term strength and stability of cemented paste backfill. Mater. Lett. 2005, 59, 3703-3709. [CrossRef]

50. Yılmaz, T.; Ercikdi, B.; Karaman, K.; Külekçi, G. Assessment of strength properties of cemented paste backfill by ultrasonic pulse velocity test. Ultrasonics 2014, 54, 1386-1394. [CrossRef]

51. Hassani, F.P.; Razavi, S.M.; Isagon, I. A study of physical and mechanical behaviour of gel fill. Cim. Bull. 2007, 100, 1-7.

52. Zhao, Y.; Taheri, A.; Karakus, M.; Chen, Z.; Deng, A. Effects of water content, water type and temperature on the rheological behaviour of slag-cement and fly ash-cement paste backfill. Int. J. Min. Sci. Technol. 2020, 30, 271-278. [CrossRef]

53. Du, X.; Feng, G.; Zhang, Y.; Wang, Z.; Guo, Y.; Qi, T. Bearing mechanism and stability monitoring of cemented gangue-fly ash backfill column with stirrups in partial backfill engineering. Eng. Struct. 2019, 188, 603-612. [CrossRef]

54. Behera, S.K.; Ghosh, C.; Mishra, D.; Singh, P.; Mishra, K.; Buragohain, J.; Mandal, P.K. Strength development and microstructural investigation of lead-zinc mill tailings based paste backfill with fly ash as alternative binder. Cem. Concr. Compos. 2020, 109, 103553. [CrossRef]

55. Benzaazoua, M.; Belem, T.; Bussière, B. Chemical factors that influence the performance of mine sulphidic paste backfill. Cem. Concr. Res. 2002, 32, 1133-1144. [CrossRef]

56. Zhao, Y.; Soltani, A.; Taheri, A.; Karakus, M.; Deng, A. Application of Slag-Cement and Fly Ash for Strength Development in Cemented Paste Backfills. Minerals 2018, 9, 22. [CrossRef]

57. Zhao, Y.; Taheri, A.; Soltani, A.; Karakus, M.; Deng, A. Strength development and strain localization behaviour of cemented paste backfills using portland cement and fly ash. Materials 2019, 3282, 2019. 